\title{
Public Investment, Growth, and Debt Sustainability: Putting Together the Pieces
}

Edward E. Buffie, Andrew Berg, Catherine Pattillo, Rafael Portillo, and Luis-Felipe Zanna 
IMF Working Paper

Research Department

Public Investment, Growth and Debt Sustainability: Putting Together the Pieces

Prepared by Edward Buffie, Andrew Berg, Catherine Pattillo, Rafael Portillo, and Luis-Felipe Zanna ${ }^{1}$

June 2012

\begin{abstract}
This Working Paper should not be reported as representing the views of the IMF.

The views expressed in this Working Paper are those of the author(s) and do not necessarily represent those of the IMF or IMF policy, or of DFID. Working Papers describe research in progress by the author(s) and are published to elicit comments and to further debate.
\end{abstract}

We develop a model to study the macroeconomic effects of public investment surges in low-income countries, making explicit: (i) the investment-growth linkages; (ii) public external and domestic debt accumulation; (iii) the fiscal policy reactions necessary to ensure debt-sustainability; and (iv) the macroeconomic adjustment required to ensure internal and external balance. Well-executed high-yielding public investment programs can substantially raise output and consumption and be self-financing in the long run. However, even if the long run looks good, transition problems can be formidable when concessional financing does not cover the full cost of the investment program. Covering the resulting gap with tax increases or spending cuts requires sharp macroeconomic adjustments, crowding out private investment and consumption and delaying the growth benefits of public investment. Covering the gap with domestic borrowing market is not helpful either: higher domestic rates increase the financing challenge and private investment and consumption are still crowded out. Supplementing with external commercial borrowing, on the other hand, can smooth these difficult adjustments, reconciling the scaling up with feasibility constraints on increases in tax rates. But the strategy may be also risky. With poor execution, sluggish fiscal policy reactions, or persistent negative exogenous shocks, this strategy can easily lead to unsustainable public debt dynamics. Front-loaded investment programs and weak structural conditions (such as low returns to public capital and poor execution of investments) make the fiscal adjustment more challenging and the risks greater.

JEL Classification Numbers: $\quad$ E62, F34, H63, O43, H54.

Keywords: Public Investment, Growth, Debt Sustainability, Fiscal Policy, Infrastructure, Aid

Mail Author’s E-Addresses: ebuffie@indiana.edu; aberg@imf.org; cpattillo@imf.org; rportillo@imf.org; fzanna@imf.org

\footnotetext{
${ }^{1}$ We thank Valerio Crispolti, Raphael Espinoza, Giovanni Ganelli, Andrew Jewell, Alvar Kangur, Chris Papageorgiou, Jens Reinke, Carlo Sdralevich, Susan Yang, and participants of the MMDG seminar of the African department at the IMF, the 2011 AERC/UNU-WIDER Macroeconomics of Foreign Aid Meeting, and the 2012 CSAE conference in Oxford for useful comments. All errors remain ours. This working paper is part of a research project on macroeconomic policy in low-income countries supported by the U.K.'s Department for International Development (DFID). Edward Buffie: Department of Economics, Indiana University, Wylie Hall Rm 105, $100 \mathrm{~S}$. Woodlawn, Bloomington, IN 47405.
} 


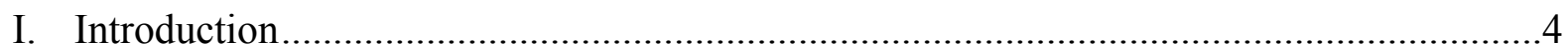

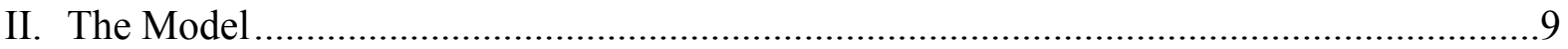

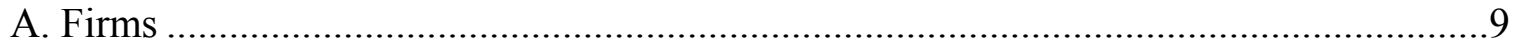

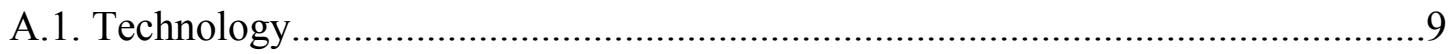

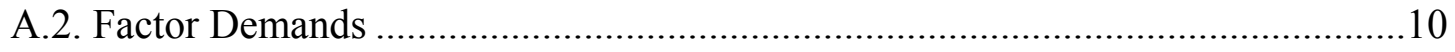

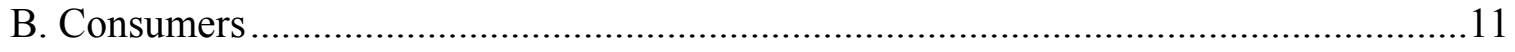

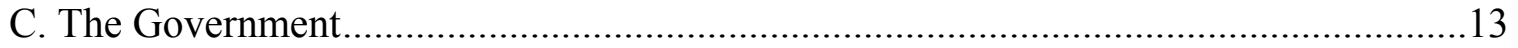

C.1. Infrastructure, Public Investment and Efficiency ................................................13

C.2. Fiscal Adjustment and the Public Sector Budget Constraint ................................14

D. Market-Clearing Conditions and External Debt Accumulation.....................................17

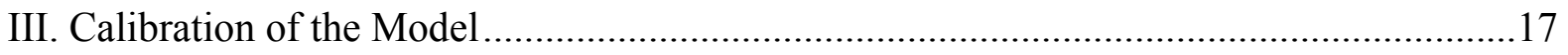

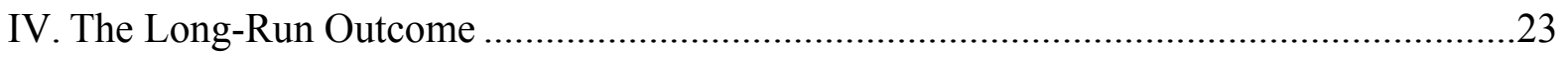

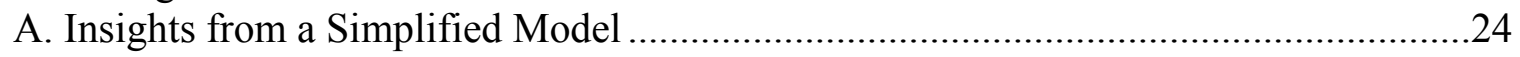

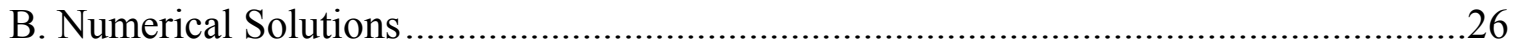

V. The Medium-Term Fiscal and Macroeconomic Adjustments under Different Financing

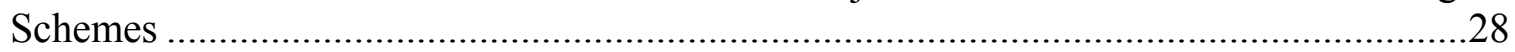

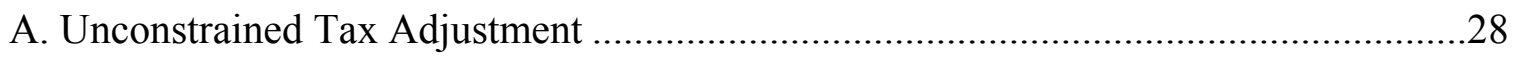

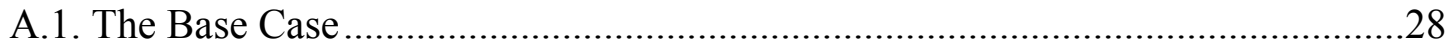

A.2. More Optimistic and Troublesome Scenarios.......................................................30

A.3. Gradually Increasing Transfers, Efficiency, and the Collection Rate of User

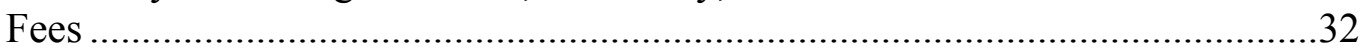

B. Constrained Tax Adjustment Combined with External Commercial Borrowing ..........36

B.1. Tax Smoothing and Private Demand Crowding Out ...........................................36

B.2. Debt Blowups: Structural and Policy Conditions ...................................................38

C. Constrained Tax Adjustment Combined with Domestic Borrowing .............................39

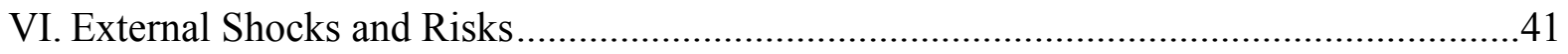

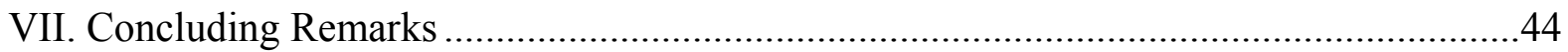

\section{Tables}

Table 1. Base Case Calibration .........................................................................................19

Table 2. Public Investment Scaling Up, Concessional Borrowing, and Grants .....................23

Table 3. Long-run Effects of Scaling up Public Investment by 3 Percent of Initial GDP .......27

\section{Figures}

Figure 1. The Long-run Outcome in the Simplified Model...................................................24

Figure 2. Base Case: Unconstrained Tax Adjustment ...........................................................2

Figure 3. Unconstrained Tax Adjustment: Optimistic and Troublesome Scenarios ................31 
Figure 4. Unconstrained Tax Adjustment: The Size of the Scaling Up..............................33

Figure 5. Unconstrained Tax Adjustment: Increasing Transfers ........................................34

Figure 6. Unconstrained Tax Adjustment versus Constrained Tax Adjustment with

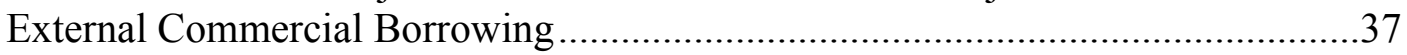

Figure 7. Constrained Tax Adjustment with External Commercial Borrowing: Varying the Structural and Policy Conditions 38

Figure 8. Constrained Tax Adjustment: Domestic Borrowing versus External Commercial Borrowing

Figure 9. External TOT Shocks: Shocks Persistence and Financing Schemes.......................41

Figure 10. TFP and Risk Premium Shocks and Risks

\section{Appendix}

A. On Public Investment Efficiency, Rates of Return, and Growth

References. 


\section{Introduction}

Many low-income countries (LICs) are facing dire infrastructure gaps. ${ }^{1}$ For the first time in decades, many also have substantial growth momentum, low debt levels, and access to nonconcessional foreign credit. Meanwhile, aid resources are not increasing as promised. ${ }^{2}$ The opportunity to borrow nonconcessionally to meet infrastructure needs has thus become very tempting. ${ }^{3}$

The risks associated with excessive borrowing to finance these public investment plans need to be considered as well. The Highly Indebted Poor Country (HIPC) and Multilateral Debt Relief initiatives (MDRI) reduced the external debt of the poorest countries by ninety percent over the past decade. This followed decades of struggle by these countries to work their way out from onerous debt levels, which were mostly accumulated in the 1970s, the last time many of them were growing rapidly and had access to new foreign lending on a large scale. Debt indicators in LICs are still far below the levels seen in the mid-90s. However, rapid accumulation of new debt in these countries - especially the increasing reliance on more expensive domestic and external commercial debt - could bring back the spectre of debt crisis, macroeconomic instability, and severely impaired development prospects. ${ }^{4}$

The IMF and World Bank (IMF-WB) use a debt sustainability framework (DSF) to identify overborrowing situations that may endanger macroeconomic stability. In the DSF, a baseline set of 20-year projections for borrowing, GDP growth, exports, and other key macroeconomic variables underpin an analysis of key debt ratios. In this debt sustainability analysis (DSA), a country is at "high risk" of debt distress if any of the debt ratios - such as debt/GDP and debt/exports - exceed a specified threshold in the baseline scenario over the 20-year horizon. The thresholds in turn have been determined based on empirical evidence linking these ratios to subsequent episodes of debt distress. ${ }^{5} \mathrm{~A}$ country is at "moderate risk" if the ratios exceed the thresholds in one of several specified alternative scenarios or "stress tests" that simulate negative growth shocks and nominal exchange rate shocks, among others. ${ }^{6}$ But, of course, judgement is used by staff when assigning risk ratings.

The DSF has helped countries monitor their risk of debt distress and sharpened the IMF-WB's assessments and policy advice, but it has been also subject to several criticisms.

\footnotetext{
${ }^{1}$ See Foster and Briceño-Garmendia (2010).

${ }^{2}$ For example, Redifer (2010) points out that the four East African countries with new Fund's Policy Support Instrument Programs (Mozambique, Rwanda, Tanzania, and Uganda), official aid has on average not increased in line with public investment spending and is not projected to do so in the next three years; therefore new financing sources, such as external commercial borrowing, must be tapped if public investment is to be scaled up.

${ }^{3}$ A recent survey by Citigroup describes the new borrowing environment: "Knowing they want to borrow money to spend on projects to close the infrastructure deficit, governments in SSA have faced a wave of lenders looking to get money out of the door and into their pockets: whether investment bankers extolling the virtues of issuing Eurobonds; apparently cheap BRIC country loans, but with long-term catches on payment implications . .." (Cowan, 2010, p.9). A call to borrow for development neeeds is endorsed by UNCTAD (2004) and EURODAD (2001, 2009), in the context of the human development approach to debt sustainability.

${ }^{4}$ See IMF and World Bank (2006) and Barkbu et al. (2008), among others.

${ }^{5}$ The thresholds depend on the quality of policies and institutes as measured by the Country Policy and Institutional Assessment (CPIA) index of the World Bank.

${ }^{6}$ See $\operatorname{IMF}(2010)$ for the most recent guidelines on the application of the DSF to LICs.
} 
One of the criticisms is that the DSF does not contain a consistent analytic framework for creating the 20-year projections. Sachs (2002), for instance, argues that "the so-called debt sustainability analysis is built on the flimsiest of foundations," arguing that it is little more than a set of accounting identities and exogenous projections. In the same vein, Eaton (2002) and Hjertholm's (2003) have raised concerns that IMF-WB's debt projections are not derived from an integrated, internally consistent macroeconomic framework. A specific aspect of this criticism is that the IMF-WB projections do not take sufficiently into account the relationship between public investment and growth. That is, the projections generally do not make an explicit linkage between the public investment that the proposed nonconcessional borrowing is meant to finance and the resulting growth that should make the operation self-financing. This inflates debt indicators, such as debt-to-GDP ratios, creates a bias toward conservative borrowing limits, and can amount "to sacrificing growth to imprecisely known debt sustainability risks" (Wyplosz, 2007).

Another concern relates to the treatment of fiscal policy in the forward-looking framework. The DSF concept of solvency requires that debt stay below the thresholds absent a "major correction" in policies. It cannot, in the view of Wyplosz (2007), be invoked to argue that a particular level of debt, or even a prolonged rising path, signifies debt distress. After all, even a very good project may take some time to pay off, and in the interim the debt ratios may exceed a given threshold. Moreover, the stress tests assume that the government does not react to shocks, contradicting evidence that primary balances in fact respond to rising public debt and potentially making the tests too conservative. ${ }^{7}$

This paper addresses these criticisms by proposing an internally consistent quantitative macroeconomic framework that may be useful in constructing the scenarios necessary for debt sustainability analysis. The model has many LIC-specific components, but it is centered on the public investmentgrowth nexus. ${ }^{8}$ In the end, judgement will be critical in making projections and scenarios for the DSF, whether through purely ad hoc forecasts or the careful calibration of the model. But the model should serve to: make explicit the assumptions underlying the projections, furthering discussions internally and with stakeholders based on different simulated scenarios; help apply empirical information, for example on project rates of return; and allow more systematic risk assessments.

In putting the model through its paces to analyze debt-led public investment scaling ups in a typical Sub-Saharan African (SSA) LIC, the paper demonstrates the importance of a coherent forward-looking analysis, with explicit policy reaction functions that may respond to debt levels. An overarching conclusion regarding the debt sustainability impact of ambitious public investment plans is that it is not enough to compare the rate of return of these plans to their cost of funding. ${ }^{9}$ Rather, the absorptive capacity of the country, the efficiency of public investment spending, the response of the private sector,

\footnotetext{
${ }^{7}$ For this evidence see Celasun et al. (2007), among others. In the current review of the DSF, Fund and World Bank staff are proposing the inclusion, on an optional basis, of a new stress test reflecting dynamic linkages between macroeconomic variables.

${ }^{8}$ The Fund acknowledges the need for strengthening analysis of the investment/growth nexus in DSAs, including through development and operationalizing models to provide a consistent way to assess the complex interlinkages (IMF and World Bank, 2009).

${ }^{9}$ Thus we disagree with Wyplosz (2007): "If external borrowing is growth enhancing, the risk of over borrowing is small, possibly inexistent. If, instead, external borrowing does not exert any favorable growth effect, and possibly stunts growth, DSA is moot . . ( p.14)".
} 
the authorities' ability to adjust taxes and spending, and other factors shape the benefits - and the debt sustainability risks - of these investment plans.

A further criticism is that the DSF-based debt limits policy is not flexible enough in allowing countries with IMF-supported programs to borrow nonconcessionally. In response, the IMF has recently made its policies more flexible. ${ }^{10}$ The question of how to move from an analysis of debt sustainability to the application of borrowing limits in IMF-supported programs is outside the scope of this paper. Rather, the sole focus here is on the macroeconomic framework - the projections and scenarios - underlying the DSF. However, we hope that the availability of more coherent medium-term framework, incorporating public investment/growth linkages, will allow better analysis and application of borrowing limits in difficult cases. ${ }^{11}$

With these goals in mind, we construct an optimizing intertemporal model that embeds features that seem crucial to capturing the main mechanisms and policy issues of interest for DSAs in LICs.

The model incorporates a neoclassical production function with private and public capital. Because public capital is productive, government spending can raise output directly and crowd in as well as crowd out private investment. The parameters of the production function determine the rate of return to installed public capital.

Several distinct features capture aspects of the challenges LIC governments have faced historically in making productive public investments. First, spending on public investment does not always imply an equivalent increase in the stock of public capital. Depending on the "efficiency" of public investment, some of the spending may be wasted or spent on poor (inframarginal) projects. In addition, we assume an "absorptive capacity" problem: due to coordination problems or supply bottlenecks during the implementation phase of public investment projects, unusually high investment rates may result in large costs overruns that affect the budget. Both efficiency and absorptive capacity play key roles in determining the final impact of public investment on growth, along with the rate of return to public capital. ${ }^{12}$

We allow for different government financing options and state explicitly the fiscal policy reactions that may ensure debt sustainability. In our analysis, we take available aid and concessional borrowing flows as exogenously given. Absent additional financing sources, the government adjusts taxes and transfers to finance the public investment scaling up. The model then considers external commercial

\footnotetext{
${ }^{10}$ The IMF has recently modified its policies on nonconcessional borrowing by LICs in the context of IMF-supported programs to reflect better the diversity of LICs and their financing patterns, and offer more flexibility depending on countries' debt vulnerabilities and public financial management capacity. See IMF(2009b) for the guidelines on debt limits in Fund-supported programs.

${ }^{11}$ The IMF and World Bank Boards have stated that until the investment-growth nexus is incorporated concerns will persist that "the DSF has unduly constrained the ability of LICs to finance their development goals." See IMF and World Bank (2009).

${ }^{12}$ As in Berg et al. (2010b), we also introduce learning-by-doing externalities in the production of both sectors, defined in terms of sectoral outputs. These externalities capture the Dutch-disease (Dutch-vigor) notion that real exchange appreciation (depreciation) may harm (help) productivity growth in the traded sector, which is a major concern in LICs that face aid surges, including substantial increases in concessional borrowing. Nevertheless, in this paper we do not elaborate on the implications of these externalities for debt sustainability.
} 
borrowing and domestic borrowing to help finance the public investment surge, with taxes and transfers responding to stabilize debt levels over time. The model allows the imposition of feasibility constraints on the pace or level of these fiscal adjustments for taxes and transfers, potentially yielding explosive debt trajectories.

Finally, the model contains a number of other features and shocks that are common in LICs and shape the macroeconomic effects of public investment surges. The model has traded and non-traded sectors and separate prices for exports and imports. These features allow an analysis of the real exchange rate and the need to achieve external and internal balance; they also permit the analysis of shocks to the terms of trade (TOT). On the private sector side, it incorporates hand-to-mouth consumers and limited access to international capital markets to capture financial market imperfections. The presence of these consumers helps break Ricardian equivalence. The limited access to international capital markets is key to making nonconcessional borrowing by the government important. With fully open capital accounts, it would not matter whether the government borrowed domestically or abroad, for example, as private agents could borrow abroad to lend to the government. In addition to TOT shocks, the model incorporates shocks to the government external debt risk premium (or world interest rates) and negative total factor productivity (TFP) shocks, as a way to model natural disaster shocks.

Because the future is uncertain, asserting that a path of public debt is unsustainable is still challenging. As Wyplosz (2007) argues "it is future balances that matter, not the past and not just the current debt level. Huge debts can be paid back, and small debts may not be sustainable, it all depends on what the primary balance will look like in the future, including the very distant future." Our model provides a logically consistent framework that helps unveil the trade-offs and potential risks associated with different types of financing and fiscal policy reactions. Given a calibration and some assumptions about structural conditions, financing options and fiscal policy reactions of a particular LIC, the model can help IMF country teams or country authorities build different scenarios to inform the DSA. This should help articulate and dissect ambitious borrowing plans that aim to push growth above historical averages along with analysis of "an alternative high-investment, low-growth payoff scenario" to counterbalance potential tendencies toward excessive optimism. ${ }^{13}$

We calibrate the model to the "average" LIC and pursue different policy experiments, whose results speak directly to many of the issues that have preoccupied the literature:

- Despite the low tax-take in LICs, increases in infrastructure investment may be self-financing in the long run. The favorable long-run effect on the budget reflects extra increases in output and revenue associated with strong crowding in of private capital. For this to happen the economy must feature strong structural conditions, such as high returns on public capital, high public investment efficiency and high collection rates of user fees, among others.

- Even very good (high rate-of-return) projects may not be fully self-financing, however, because most of the direct benefits of the higher public capital accrue to the private sector and average tax collection rates are quite low.

\footnotetext{
${ }^{13}$ On calls to pursue alternative scenarios in DSAs, see IMF and World Bank (2006) and Barkbu et al. (2008).
} 
- Even if the investment program is self-financing in the long run, transition problems can be formidable. Absent additional borrowing or aid, the revenue gains from growth will not materialize soon enough to obviate the need for difficult fiscal adjustments on the transition path, especially when the scaling up is front-loaded. Tax rates may have to increase sharply, crowding out private investment and consumption and further aggravating the near-term fiscal challenge.

- Nonconcessional external borrowing can smooth away difficult fiscal adjustments, reconciling scaling up of public investment with constraints on feasible increases in tax rates (or cuts in spending). But this strategy may be risky. Low rates of return, inefficient public investment, sluggish fiscal adjustment, or low absorptive capacity can easily lead to unsustainable public debt.

- Borrowing in the domestic debt market is ineffective in smoothing the path of fiscal adjustment and avoiding private sector crowding out. It does not provide additional resources from abroad, so the public investment scaling up still requires a decline in private consumption and investment in the first few years. In addition, interest rates are likely to be higher than with external borrowing, which further deteriorates the prospects for private investment.

- Commercial borrowing can make the economy more vulnerable to macroeconomic instability in the presence of persistent unexpected shocks, such as to the TOT, TFP, or public debt risk premium. These shocks are less prone to ignite explosive paths of public debt when aid or concessional lending responds positively to negative shocks.

- Because there is uncertainty about the underlying parameters and because of exogenous shocks, size matters. If the increase in public investment is small relative to the size of the economy, then the risk of debt distress does not depend much on these parameters or on the shocks. But as the investment grows larger, they become more critical to the risks of debt distress.

Our work distinguishes itself from the literature that studies the macroeconomic effects of public investment by analyzing the trade-offs of different types of public debt, while underscoring the role for debt sustainability of i) structural and policy conditions and ii) exogenous shocks. The seminal works by Barro (1990), Sala-i-Martin (1992), Futagami et al. (1993) and Glomm and Ravikumar (1994) analyze the growth impact of public investment in the context of endogenous growth models. More recently, Chatterjee and Turnovsky (2007) and Agenor (2010), among others, have relied on these endogenous growth setups to explore the importance of some LIC-specific features for the public capital accumulation and growth nexus. The former explore the importance of tied vs untied aid, while the latter emphasizes the role of infrastructure network effects and the efficiency of public investment. All these models, however, assume government balanced budget rules, thereby abstracting from public debt accumulation. On the other hand, Turnovsky (1999), Greiner et al. (2005) and Greiner (2007), among others, incorporate government debt in their endogenous growth framework. In contrast to our work, they do not allow for different financing schemes and ignore the role played by the structural and policy conditions for debt sustainability. Finally, the works by Adam and Bevan (2006), Cerra et al. (2008), and Berg et al. (2010b), among others, look into the macroeconomic effects of aid-financed public investment expansions. But here again, external public debt accumulation is not allowed and, therefore, the interaction of structural and policy conditions with debt dynamics is missing. 
Finally, our paper is also related to the literature about debt sustainability, but our emphasis is on LICs. Celasun et al. (2007), Garcia and Rigobon (2005), and Mendoza and Oviedo (2004), among others, focus on emerging economies; while Bohn (1998) and Ghosh et al. (2011), among others, concentrate on advanced economies.

The main body of the paper is organized into seven sections. In Sections II and III we explicate the model and calibrate it to the "average" LIC. Following these, Section IV analyzes the long-run impact of a permanent, large increase in public investment. Then Sections V and VI investigate the medium-term trade-offs and potential risks associated with the different financing schemes. Finally, Section VII concludes.

\section{The Model}

Our framework is the standard two-sector model of a small open economy embellished with multiple types of public sector debt and multiple tax and spending variables. The country produces a traded good $q_{x}$ and a non-traded good $q_{n}$ from private capital $k$, labor $L$, and government-supplied infrastructure $z$. Besides these domestically produced goods, agents can import a traded good for consumption $c_{m}$ and machines $\mathfrak{m}_{m m}$ to produce factories (private capital) and infrastructure (public capital). All quantity variables except labor are detrended by $(1+g)^{t}$, where $g$ is the exogenous long-run growth rate of real GDP. ${ }^{14}$ A composite good produced abroad is the numeraire, with the associated consumer price index (CPI) denoted by $P_{t}^{*}$, which is assumed to be equal to one for simplicity. Since the time horizon for the DSA is about 20 years, the model abstracts from money and all nominal rigidities. ${ }^{15}$

We lay out the model in stages, starting with the specification of technology.

\section{A. Firms}

\section{A.1. Technology}

In each sector $j$, the representative firm use Cobb-Douglas technologies to convert labor $L_{j, t}$, private capital $k_{j, t-1}$, and effectively productive infrastructure $z_{t-1}^{e}$, which is a public good, into output: ${ }^{16}$

$$
q_{x, t}=A_{x, t}\left(z_{t-1}^{e}\right)^{\psi_{x}}\left(k_{x, t-1}\right)^{\alpha_{x}}\left(L_{x, t}\right)^{1-\alpha_{x}}
$$

and

$$
q_{n, t}=A_{n, t}\left(z_{t-1}^{e}\right)^{\psi_{n}}\left(k_{n, t-1}\right)^{\alpha_{n}}\left(L_{n, t}\right)^{1-\alpha_{n}} .
$$

\footnotetext{
${ }^{14}$ In the long run all variables, including real GDP, grow at the same exogenous growth rate $g$. However, in the short to medium term, significant public and private capital accumulation, resulting from scaling up investment, implies that the growth rate of the economy can go above $g$.

${ }^{15}$ We are currently working on a version that includes money and nominal price rigidities along the lines of the model in Berg et al. (2010b).

${ }^{16}$ We assume Cobb-Douglas technologies but, to some extent, we do not expect significant changes in our results by considering CES technologies.
} 
The firm productivities are expressed as

$$
A_{x, t}=a_{x}\left(\frac{q_{x, t-1}^{I}}{\bar{q}_{x}^{I}}\right)^{\sigma_{x}}\left(k_{x, t-1}^{I}\right)^{\xi_{x}} \quad \text { and } \quad A_{n, t}=a_{n}\left(\frac{q_{n, t-1}^{I}}{\bar{q}_{n}^{I}}\right)^{\sigma_{n}}\left(k_{n, t-1}^{I}\right)^{\xi_{n}}
$$

and feature sector-specific externalities of two types, with variables with the superindex $I$ denoting sectoral quantities: a "static" externality associated with private capital accumulation- $\left(k_{j, t-1}^{I}\right)^{\xi_{j}}$ for $j=x, n$-as in Arrow (1962); and a "learning-by-doing" externality that depends on the deviations of the lagged sector output from the (initial) steady state $-\left(\frac{q_{j, t-1}^{I}}{\bar{q}_{j}^{I}}\right)^{\sigma j}$ for $j=x, n$. When the latter externality is greater in the traded sector than that in the non-traded sector, then it can capture the notion of Dutch-disease as in Berg et al. (2010b), where a decline in the traded sector imposes an economic cost through a sectoral loss in total-factor productivity (TFP).

Factories and infrastructure are built by combining one imported machine with $a_{j}(j=k, z)$ units of a non-traded input (e.g., construction). The supply prices of private capital and infrastructure are thus

$$
P_{k, t}=P_{m m, t}+a_{k} P_{n, t}
$$

and

$$
P_{z, t}=P_{m m, t}+a_{z} P_{n, t}
$$

where $P_{n}$ is the (relative) price of the non-traded good and $P_{m m}$ is the (relative) price of imported machinery.

\section{A.2. Factor Demands}

Competitive profit-maximizing firms equate the marginal value product of each input to its factor price. This yields the input demand equations

$$
\begin{gathered}
P_{n, t}\left(1-\alpha_{n}\right) \frac{q_{n, t}}{L_{n, t}}=w_{t}, \\
P_{x, t}\left(1-\alpha_{x}\right) \frac{q_{x, t}}{L_{x, t}}=w_{t}, \\
P_{n, t} \alpha_{n} \frac{q_{n, t}}{k_{n, t-1}}=r_{n, t},
\end{gathered}
$$

and

$$
P_{x, t} \alpha_{x} \frac{q_{x, t}}{k_{x, t-1}}=r_{x, t}
$$

where $w$ is the wage and $r_{j}$ is the rental earned by capital in sector $j$. Labor is intersectorally mobile, so the same wage appears in (5) and (6). Capital is sector-specific, but $r_{x}$ differs from $r_{n}$ only on the transition path. After adjustment is complete and $k_{x}$ and $k_{n}$ have settled at their equilibrium levels, the rentals are equal. 


\section{B. Consumers}

There are two types of private agents, savers and non-savers, with the former and the latter distinguished by the superscripts $\mathfrak{s}$ and $\mathfrak{h}$, respectively. Labor supply of savers is fixed at $L^{\mathfrak{s}}$ while that of non-savers is $L^{\mathfrak{h}}=a L^{\mathfrak{s}}$ with $a>0$. The two types of agents consume the domestic traded good $c_{x, t}^{i}$, the foreign traded good $c_{m, t}^{i}$, and the domestic non-traded good $c_{n, t}^{i}$ for $i=\mathfrak{s}, \mathfrak{h}$. These goods are combined into a CES basket

$$
c_{t}^{i}=\left[\rho_{x}^{\frac{1}{\epsilon}}\left(c_{x, t}^{i}\right)^{\frac{\epsilon-1}{\epsilon}}+\rho_{m}^{\frac{1}{\epsilon}}\left(c_{m, t}^{i}\right)^{\frac{\epsilon-1}{\epsilon}}+\left(\rho_{n}\right)^{\frac{1}{\epsilon}}\left(c_{n, t}^{i}\right)^{\frac{\epsilon-1}{\epsilon}}\right]^{\frac{\epsilon}{\epsilon-1}} \quad \text { for } i=\mathfrak{s}, \mathfrak{h}
$$

where $\rho_{x}, \rho_{m}$, and $\rho_{n}$ are CES distribution parameters and $\epsilon$ is the intratemporal elasticity of substitution. In addition $\rho_{n}=1-\rho_{x}-\rho_{m}$.

The (relative) CPI associated with the basket (9) is $P_{t}=\left[\rho_{x} P_{x, t}^{1-\epsilon}+\rho_{m} P_{m, t}^{1-\epsilon}+\rho_{n} P_{n, t}^{1-\epsilon}\right]^{\frac{1}{1-\epsilon}}$, while the demand functions for each good can be expressed as

$$
c_{j, t}^{i}=\rho_{j}\left(\frac{P_{j, t}}{P_{t}}\right)^{-\epsilon} c_{t}^{i} \quad \text { for } \quad j=x, m, n \quad \text { and } \quad i=\mathfrak{s}, \mathfrak{h} .
$$

Savers can invest $i_{x}$ and $i_{n}$ amounts in private capital that depreciates at the rate $\delta$, pay user fees charged for infrastructure services according to $\mu z^{e}$, can buy domestic bonds $b$-which cannot be bought in any market by foreigners - and pay a real interest rate $r$, and can contract foreign debt $b^{*}$ that charges an exogenous real interest rate $r^{*}$. They solve the intertemporal problem

$$
\operatorname{Max} \sum_{t=0}^{\infty} \beta^{t} \frac{\left(c_{t}^{\mathfrak{s}}\right)^{1-1 / \tau}}{1-1 / \tau}
$$

subject to

$$
\begin{gathered}
P_{t} b_{t}^{\mathfrak{s}}-b_{t}^{\mathfrak{s} *}=r_{x, t} k_{x, t-1}^{\mathfrak{s}}+r_{n, t-1} k_{n, t-1}^{\mathfrak{s}}+w_{t} L_{t}^{\mathfrak{s}}+\frac{\mathcal{R}_{t}}{1+a}+\frac{\mathcal{I}_{t}}{1+a}-\frac{1+r_{t-1}^{*}}{1+g} b_{t-1}^{\mathfrak{s} *}+\frac{1+r_{t-1}}{1+g} P_{t} b_{t-1}^{\mathfrak{s}} \\
-P_{k, t}\left(i_{x, t}^{\mathfrak{s}}+i_{n, t}^{\mathfrak{s}}+A C_{x, t}^{\mathfrak{s}}+A C_{n, t}^{\mathfrak{s}}\right)-P_{t} c_{t}^{\mathfrak{s}}\left(1+h_{t}\right)-\mu z_{t-1}^{e}-\mathcal{P}_{t}^{\mathfrak{s}}-\Phi_{t}^{\mathfrak{s}} \\
(1+g) k_{x, t}^{\mathfrak{s}}=i_{x, t}^{\mathfrak{s}}+(1-\delta) k_{x, t-1}^{\mathfrak{s}}
\end{gathered}
$$

and

$$
(1+g) k_{n, t}^{\mathfrak{s}}=i_{n, t}^{\mathfrak{s}}+(1-\delta) k_{n, t-1}^{\mathfrak{s}},
$$

where $\beta=1 /\left[(1+\varrho)(1+g)^{(1-\tau) / \tau}\right]$ is the discount factor; $\varrho$ is the pure time preference rate; $\tau$ is the intertemporal elasticity of substitution; $\delta$ is the depreciation rate; $\mathcal{R}$ are remittances; $\mathcal{T}$ are (net) 
transfers; $h$ denotes the consumption value added tax (VAT); and $\Phi^{\mathfrak{s}}$ are profits from domestic firms. Remittances and transfers are proportional to the agent's share in aggregate employment. Observe that in the budget constraint (10), the trend growth rate appears in several places in (10)-(12), reflecting the fact that some variables are dated at $t$ and others at $t-1$ and that $P_{t}$ multiplies $b_{t}^{\mathfrak{s}}$ and $b_{t-1}^{\mathfrak{s}}$ because domestic bonds are indexed to the price level. ${ }^{17}$ Also note that there are adjustment costs incurred in changing the capital stock $-A C_{j, t}^{\mathfrak{s}} \equiv \frac{v}{2}\left(\frac{i_{j, t}^{\mathfrak{s}}}{k_{j, t-1}^{\mathfrak{s}}}-\delta-g\right)^{2} k_{j, t-1}^{\mathfrak{s}}$, for $j=x, n$ and with $v>0$ - and portfolio adjustment costs associated with foreign liabilities $-\mathcal{P}_{t}^{\mathfrak{s}} \equiv \frac{\eta}{2}\left(b_{t}^{\mathfrak{s *}}-\bar{b}^{\mathfrak{s} *}\right)^{2}$, where $\bar{b}^{*}$ is the (initial) steady-state value of the private foreign liabilities. ${ }^{18}$

The choice variables in the optimization problem are $c_{t}^{\mathfrak{s}}, b_{t}^{\mathfrak{s}}, b_{t}^{\mathfrak{s} *}, i_{j, t}^{\mathfrak{s}}$, and $k_{j, t}^{\mathfrak{s}}$ for $j=x, n$. Routine manipulations of the first-order conditions deliver:

$$
\begin{gathered}
c_{t}^{\mathfrak{s}}=c_{t+1}^{\mathfrak{s}}\left(\beta \frac{1+r_{t}}{1+g} \frac{1+h_{t}}{1+h_{t+1}}\right)^{-\tau}, \\
\left(1+r_{t}\right) \frac{P_{t+1}}{P_{t}}=\frac{1+r_{t}^{*}}{\left[1-\eta\left(b_{t}^{\mathfrak{s} *}-\bar{b}^{\mathfrak{s} *}\right)\right]}, \\
\frac{r_{x, t+1}}{P_{k, t+1}}+1-\delta+v \Upsilon_{x, t+1}^{\mathfrak{s}}\left(\frac{i_{x, t+1}^{\mathfrak{s}}}{k_{x, t}^{\mathfrak{s}}}+1-\delta\right)-\frac{v}{2}\left(\Upsilon_{x, t+1}^{\mathfrak{s}}\right)^{2}=\left(1+r_{t}\right) \frac{P_{t+1}}{P_{t}} \frac{P_{k, t}}{P_{k, t+1}}\left(1+v \Upsilon_{x, t}^{\mathfrak{s}}\right),
\end{gathered}
$$

and

$$
\frac{r_{n, t+1}}{P_{k, t+1}}+1-\delta+v \Upsilon_{n, t+1}^{\mathfrak{s}}\left(\frac{i_{n, t+1}^{\mathfrak{s}}}{k_{n, t}^{\mathfrak{s}}}+1-\delta\right)-\frac{v}{2}\left(\Upsilon_{n, t+1}^{\mathfrak{s}}\right)^{2}=\left(1+r_{t}\right) \frac{P_{t+1}}{P_{t}} \frac{P_{k, t}}{P_{k, t+1}}\left(1+v \Upsilon_{n, t}^{\mathfrak{s}}\right)
$$

where $\Upsilon_{j, t}^{\mathfrak{s}}=\left(\frac{i_{j, t}^{\mathfrak{s}}}{k_{j, t-1}^{\mathfrak{s}}}-\delta-g\right)$ for $j=x, n$. Each of these equations admits a straightforward intuitive interpretation. Equation (13) is a slightly irregular Euler equation in which the slope of the consumption path depends on the real interest rate adjusted for trend growth and on changes in the VAT. The other three equations are arbitrage conditions. Equation (14) equalizes the real interest rate on domestic bonds to the real interest rate on foreign private debt, adjusted by portfolio costs. Similarly, equations (15) and (16) require the return on capital in each sector, net of marginal adjustment costs, to equal the real interest rate.

In our modelling decisions, we balance realism and flexibility in introducing portfolio adjustment costs to capture different degrees of integration of the private sector into world capital markets. Equation (14) implicitly defines a private demand for foreign debt, which can be explicitly expressed as:

$$
\eta\left(b_{t}^{\mathfrak{s} *}-\bar{b}^{\mathfrak{s *}}\right)=1-\frac{1+r_{t}^{*}}{\left(1+r_{t}\right) \frac{P_{t+1}}{P_{t}}} .
$$

\footnotetext{
${ }^{17}$ The convention for detrending the capital stocks differs from that for other variables. Because $K_{j, t-1}^{\mathfrak{s}}$ - the capital stock before detrending - is the capital stock in use at time $t$, we define $k_{j, t-1}^{\mathfrak{s}} \equiv K_{j, t-1}^{\mathfrak{s}} /(1+g)^{t}$. Under this convention, $\bar{\imath}_{j}^{\mathfrak{s}}=(\delta+g) \bar{k}_{j}^{\mathfrak{s}}$ in the long run - as required for the capital stock to grow at the trend growth rate $g$.

${ }^{18}$ For simplicity, we assume that adjustment costs are zero when the capital stock grows at the trend growth rate $g$. This ensures that adjustment costs are zero across steady states as in models that ignore trend growth.
} 
In this equation, the value of $\eta$ controls the degree of capital mobility. For some emerging market economies, a low $\eta$ may be appropriate reflecting an open capital account. Elastic capital flows then keep the domestic rate close to the foreign rate. In LICs, where $\eta$ is comparatively big, the capital account is fairly closed, and the private sector has limited capacity to borrow from abroad. ${ }^{19}$

In addition, we assume that on its foreign debt the private sector pays a constant premium $\mathfrak{u}$ over the interest rate that the government pays on external commercial debt $r_{d c}$, so

$$
r_{t}^{*}=r_{d c, t}+\mathfrak{u} .
$$

This specification together with (14) allows us to match the low capital and investment ratios observed in LICs. The reason is that at the steady state the domestic interest rate $r$ and the foreign rate $r^{*}$ are equal, meaning that $\bar{r}=\bar{r}_{d c}+\mathfrak{u}$. Thus even if $\bar{r}_{d c}$ is low, by picking an appropriate $\mathfrak{u}$, we can obtain a somewhat high domestic real interest rate $\bar{r}$ and, consequently, a high return on private capital. But because of decreasing returns, this high return implies realistically that the ratios of the capital stock and investment to GDP must be low at the initial steady-state equilibrium.

Non-savers have the same utility function as that of savers and consume all of their income from wages, remittances, and transfers each period. The non-saver's budget constraint then reads

$$
\left(1+h_{t}\right) P_{t} c_{t}^{\mathfrak{h}}=w_{t} L^{\mathfrak{h}}+\frac{a}{1+a}\left(\mathcal{R}_{t}+\mathcal{T}_{t}\right)
$$

In specifying this part of the model we have aimed for realism combined with flexibility and generality. The realism of hand-to-mouth consumers (non-savers) is indisputable given that in LICs a substantial portion of households fall into this category. ${ }^{20}$ From the modeling perspective their inclusion allows us to break Ricardian equivalence.

We aggregate across both types of households, so $x_{t}=x_{t}^{\mathfrak{s}}+x_{t}^{\mathfrak{h}}$ for $x_{t}=c_{t}, c_{l, t}, L_{t}, b_{t}^{*}, b_{t}, i_{j, t}, k_{j, t}$, $A C_{j, t}, \mathcal{P}_{t}, \Phi_{t}$, and the subindices $l=x, n, m$ and $j=x, n$. Bear in mind that $b_{t}^{\mathfrak{h} *}=b_{t}^{\mathfrak{h}}=i_{j, t}^{\mathfrak{h}}=k_{j, t}^{\mathfrak{h}}=$ $A C_{j, t}^{\mathfrak{h}}=\mathcal{P}_{t}^{\mathfrak{h}}=\Phi_{t}^{\mathfrak{h}}=0$ for $j=x, n$.

\section{The Government}

\section{C.1. Infrastructure, Public Investment and Efficiency}

Casual observation and indirect empirical evidence support the conjecture in Hulten (1996) and Pritchett (2000): often the productivity of infrastructure is high but the return on public investment very low for the simple reason that a good deal of public investment spending does not increase the stock of productive capital. Measurement error introduced by equating growth of productive capital with net investment can explain why estimated TFP growth is zero or negative in many LDCs,

\footnotetext{
${ }^{19}$ From a technical point of view, the portfolio costs also help to ensure stationarity of $b_{t}^{\mathfrak{s *}}$. See Schmitt-Grohé and Uribe (2003) for alternative methods to ensure stationarity of net foreign assets.

${ }^{20}$ For instance the 2009 Steadman Survey finds that 62 percent of Ugandans do not have access to financial services.
} 
as suggested by Pritchett (2000); and why empirical studies generally find a much stronger positive relationship between growth and physical indicators of infrastructure than between growth and capital stock series calculated via the perpetual inventory method, as reviewed by Straub (2008). ${ }^{21}$

We thus allow for inefficiencies in public capital creation. Public investment $i_{z}$ produces additional infrastructure $z$ according to:

$$
(1+g) z_{t}=(1-\delta) z_{t-1}+i_{z, t},
$$

but some of the newly built infrastructure may not be economically valuable productive infrastructure, since effectively productive capital $z_{t}^{e}$, which is actually used in technologies (1) and (2), evolves according to:

$$
z_{t}^{e}=\bar{s} \bar{z}+s\left(z_{t}-\bar{z}\right), \quad \text { with } \quad \bar{s} \in[0,1] \quad \text { and } \quad s \in[0,1]
$$

where $\bar{s}$ and $s$ are parameters of efficiency at and off steady state, and $\bar{z}$ is public capital at the (initial) steady state.

Note that by combining equations (18) and (19), we obtain

$$
(1+g) z_{t}^{e}=(1-\delta) z_{t-1}^{e}+s\left(i_{z, t}-\bar{\imath}_{z}\right)+\overline{s i}_{z},
$$

where $\bar{l}_{z}=(\delta+g) \bar{z}$ is the public investment at the (initial) steady state. This is the same specification for public investment inefficiencies as that of Berg et al. (2010b), and it is similar to the one in Agenor (2010). Since $s \in[0,1]$, this specification makes clear that one dollar of additional public investment $\left(i_{z, t}-\bar{\imath}_{z}\right)$ does not translate into one dollar of effectively productive capital $\left(z_{t}^{e}\right)$. For the simulations below, we assume $\bar{s}=0.6$ and $s=0.6$. These values are slightly higher that the estimates of Arestoff and Hurlin (2006) for some emerging economies. In principle, the public investment management quality index of Dabla-Norris et al. (2011) could help calibrate this parameter.

\section{C.2. Fiscal Adjustment and the Public Sector Budget Constraint}

The government spends on transfers, debt service, and infrastructure investment. It collects revenue from the consumption VAT and from user fees for infrastructure services, which are expressed as a fixed multiple/fraction $f$ of recurrent costs, that is $\mu=f \delta P_{z o}$. When revenues fall short of expenditures, the resulting deficit is financed through domestic borrowing $\Delta b_{t}=b_{t}-b_{t-1}$, external concessional borrowing $\Delta d_{t}=d_{t}-d_{t-1}$, or external commercial borrowing $\Delta d_{c, t}=d_{c, t}-d_{c, t-1}$ viz.:

$$
\begin{aligned}
P_{t} \Delta b_{t}+\Delta d_{c, t}+\Delta d_{t}= & \frac{r_{t-1}-g}{1+g} P_{t} b_{t-1}+\frac{r_{d, t-1}-g}{1+g} d_{t-1}+\frac{r_{d c, t-1}-g}{1+g} d_{c, t-1} \\
& +P_{z, t} \mathbb{I}_{z, t}+\mathcal{T}_{t}-h_{t} P_{t} c_{t}-\mathcal{G}_{t}-\mathcal{N}_{t}-\mu z_{t-1}^{e}
\end{aligned}
$$

\footnotetext{
${ }^{21}$ To understand the role of efficiency, it may be useful to imagine that all the available public investment projects at a given point in time are ranked from highest to lowest rate of return. In an efficient investment process, an additional dollar is spent on the best available project. It is possible, though, because of incompetence, corruption, or imperfect information, that a government may choose worse projects. A lower efficiency is a measure of the degree of deviation from the optimal process. A complementary way to think about efficiency is simply that a fraction of spending is simply wasted, e.g. misclassified as investment when it in fact just covers transfers to civil servants.
} 
where $d, d c, \mathcal{G}$, and $\mathcal{N}$ denote concessional debt, external commercial debt, grants, and natural resource revenues (if any); ${ }^{22}$ and $r_{d}$ and $r_{d c}$ are the real interest rates (in dollars) on concessional and commercial loans. The interest rate on concessional loans is assumed to be constant $r_{d, t}=r_{d}$, while the interest rate on external commercial debt incorporates a risk premium that depends on the deviations of the external public debt to GDP ratio $\left(\frac{d_{t}+d_{c, t}}{y_{t}}\right)$ from its (initial) steady-state value $\left(\frac{\bar{d}+\bar{d}_{c}}{\bar{y}}\right)$. That is,

$$
r_{d c, t}=r^{f}+v_{g} e^{\eta_{g}\left(\frac{d_{t}+d_{c, t}}{y_{t}}-\frac{\bar{d}+\bar{d}_{c}}{\bar{y}}\right)},
$$

where $r^{f}$ is a risk-free world interest rate and $y_{t}=P_{x, t} q_{x, t}+P_{n, t} q_{n, t}$ is GDP. Van der Ploeg and Venables (2011) provide positive estimates for $\eta_{g}$. But note by setting $v_{g}>0$ and $\eta_{g}=0$, our specification embeds the case of an exogenous risk premium that does depend on public debt.

The term $P_{z, t} \mathbb{I}_{z, t}$ in the budget constraint (21) corresponds to public investment outlays including costs overruns associated with absorptive capacity constraints. It is defined as

$$
\mathbb{I}_{z, t}=\mathcal{H}_{t}\left(i_{z, t}-\bar{\imath}_{z}\right)+\bar{\imath}_{z}
$$

Because skilled administrators are in scarce supply in LICs, ambitious public investment programs are often plagued by poor planning, weak oversight, and myriad coordination problems, all of which contribute to large cost overruns during the implementation phase. ${ }^{23}$ To capture this, we multiply new investment $\left(i_{z, t}-\bar{\imath}_{z}\right)$ by $\mathcal{H}_{t}=\left(1+\frac{i_{z, t}}{z_{t-1}}-\delta-g\right)^{\phi}$, where $\phi \geq 0$ determines the severity of the the absorptive capacity — or "bottleneck" - constraint in the public sector. The constraint affects only implementation costs for new projects: in a steady state, $\left(1+\frac{\bar{t}_{z}}{\bar{z}}-\delta-g\right)^{\phi}=1$ as $\bar{\imath}_{z}=(\delta+g) \bar{z}$.

Policy makers accept all concessional loans proffered by official creditors. The borrowing and amortization schedule for these loans is fixed exogenously. Given the paths for public investment and concessional borrowing, the fiscal gap before policy adjustment $\left(\mathfrak{G} \mathfrak{a} \mathfrak{p}_{t}\right)$ can be defined as:

$$
\mathfrak{G} \mathfrak{a p}_{t}=\frac{1+r_{d}}{1+g} d_{t-1}-d_{t}+\frac{r_{d c, t-1}-g}{1+g} d c_{t-1}+\frac{r_{t-1}-g}{1+g} P_{t} b_{t-1}+P_{z, t} \mathbb{I}_{t}+\mathcal{T}_{o}-h_{o} P_{t} c_{t}-\mathcal{G}_{t}-\mathcal{N}_{t}-\mu z_{t-1}^{e} .
$$

That is, $\mathfrak{G} \mathfrak{a p} p_{t}$ corresponds to expenditures (including interest rate payments on debt) less revenues and concessional borrowing, when transfers and taxes are kept at their initial levels $\mathcal{T}_{o}$ and $h_{o}$, respectively. Using this definition, we can rewrite the budget constraint (21), in any given year, as:

$$
\mathfrak{G} \mathfrak{a p} p_{t}=P_{t} \Delta b_{t}+\Delta d_{c, t}+\left(h_{t}-h_{o}\right) P_{t} c_{t}-\left(\mathcal{T}_{t}-\mathcal{T}_{o}\right)
$$

In the short/medium run, this gap $\mathfrak{G} \mathfrak{a} \mathfrak{p}_{t}$ in $(24)$ can be covered by domestic and/or external commercial borrowing $P_{t} \Delta b_{t}+\Delta d_{c, t}$, tax adjustments $\left(h_{t}-h_{o}\right) P_{t} c_{t}$, and/or transfers adjustments $-\left(\mathcal{T}_{t}-\mathcal{T}_{o}\right)$. For the sake of comparing different borrowing schemes, in the experiments below, we will

\footnotetext{
${ }^{22}$ We model natural resources revenues as a net foreign transfer, following Dagher et al. (2012). As such the measure of GDP used below corresponds to non-oil GDP. For a more comprehensive analysis of oil production, foreign investment, and managing natural resources in LICs see Berg et al. (2012).

${ }^{23}$ Development agencies report that cost overruns of $35 \%$ and more are common for new projects in Africa. The most important factor by far is inadequate competitive bidding for tendered contracts. See Foster and Briceno-Garmendia (2010).
} 
focus on cases where part of this gap can be filled with either external commercial loans or domestic loans, but not with both at the same time.

Debt sustainability requires, however, that the VAT and transfers eventually adjust to cover the entire gap (i.e., $P_{t} \Delta b_{t}+\Delta d_{c, t}=0$ ). We let policy makers divide the burden of adjustment (net windfall when $\mathfrak{G} \mathfrak{a} \mathfrak{p}_{t}<0$ ) between transfers cuts and tax increases. The adjustments, defined below according to some reaction functions, have as part of their targets the following debt-stabilizing values for transfers and the VAT

$$
h_{t}^{\text {target }}=h_{o}+(1-\lambda) \frac{\mathfrak{G} \mathfrak{a} \mathfrak{p}_{t}}{P_{t} c_{t}}
$$

and

$$
\mathcal{T}_{t}^{\text {target }}=\mathcal{T}_{o}-\lambda \mathfrak{G} \mathfrak{a} \mathfrak{p}_{t},
$$

where $\lambda$ is a policy parameter that splits the fiscal adjustment between taxes and transfers and therefore satisfies $0 \leq \lambda \leq 1$. For the extreme case of $\lambda=0$ (respectively $\lambda=1$ ) all the adjustment falls on taxes (respectively transfers).

Taxes and transfers are defined according to the following reaction functions:

$$
h_{t}=\operatorname{Min}\left\{h_{t}^{r}, h^{u}\right\}
$$

and

$$
\mathcal{T}_{t}=\operatorname{Max}\left\{\mathcal{T}_{t}^{r}, \mathcal{T}^{l}\right\}
$$

where $h^{u}$ is a ceiling on taxes, $\mathcal{T}^{l}$ is a floor for transfers, and $h_{t}^{r}$ and $\mathcal{T}_{t}^{r}$ are determined by the fiscal rules

$$
h_{t}^{r}=h_{t-1}+\lambda_{1}\left(h_{t}^{\mathrm{target}}-h_{t-1}\right)+\lambda_{2} \frac{\left(x_{t-1}-x^{\mathrm{target}}\right)}{y_{t}}, \quad \text { with } \quad \lambda_{1}, \lambda_{2}>0
$$

and

$$
\mathcal{T}_{t}^{r}=\mathcal{T}_{t-1}+\lambda_{3}\left(\mathcal{T}_{t}^{\text {target }}-\mathcal{T}_{t-1}\right)-\lambda_{4}\left(x_{t-1}-x^{\text {target }}\right), \quad \text { with } \quad \lambda_{3}, \lambda_{4}>0,
$$

with $y=P_{n} q_{n}+P_{x} q_{x}$ and $x=b$ or $d_{c}$, depending on whether the rules respond to domestic debt or commercial debt. The target for debt $x^{\text {target }}$ is given exogenously. The ceiling $h^{u}$ on taxes and the floor $\mathcal{T}^{l}$ on transfers can also have discrete jumps over time, as we show below. ${ }^{24}$ This allows us to model staggered tax and transfers structures.

Given the targets, the reaction functions defined in (27)-(30) together with the budget constraint (24) embody the core policy dilemma. Fiscal adjustment is painful, especially when administered suddenly in large doses. The government would prefer therefore to phase-in tax increases and expenditure cuts slowly $\left(\lambda_{1}>0\right.$ and $\left.\lambda_{3}>0\right)$. Since fiscal adjustment is gradual, the debt instrument that varies endogenously to satisfy the government budget constraint may rise above its target level in the time it takes $h_{t}$ and $\mathcal{T}_{t}$ to reach $h_{t}^{\text {target }}$ and $\mathcal{T}_{t}^{\text {target }}$. When this happens, the transition path includes a phase in which $\mathcal{T}_{t}<\mathcal{T}_{t}^{\text {target }}$ and/or $h_{t}>h_{t}^{\text {target }}$ to generate the fiscal surpluses needed to pay down the debt. In addition, and despite the fact that the rules respond to debt (i.e., $\lambda_{2}>0$ and $\lambda_{4}>0$ ), if the government moves too slowly (i.e., $\lambda_{1}$ and $\lambda_{3}$ are too low), or if the bounds $h^{u}$ and $\mathcal{T}^{r}$ constrain

\footnotetext{
${ }^{24}$ For instance, to introduce discrete jumps in the cap on taxes we can respecify the rule as $h_{t}=\operatorname{Min}\left\{h_{t}^{r}, h_{t}^{u}\right\}$, where $h_{t}^{u}=h_{o}^{u}+\Delta h_{t}^{u}, h_{o}^{u}$ is the initial cap and $\Delta h_{t}^{u}$ is a discrete jump (shock) at time $t$, which can be temporary or permanent.
} 
adjustment too much, interest payments will rise faster than revenue net of transfers, causing the debt to grow explosively. Large debt-financed increases in public investment are undeniably risky-the economy converges to a stationary equilibrium only if policy makers win the race against time.

\section{Market-Clearing Conditions and External Debt Accumulation}

Flexible wages and prices ensure that demand continuously equals supply in the labor market

$$
L_{x}+L_{n}=L,
$$

where the labor supply $L=L^{\mathfrak{s}}+L^{\mathfrak{h}}$ is fixed.

In the non-tradables market, after aggregating across types of consumers, we obtain

$$
q_{n, t}=\rho_{n}\left(\frac{P_{n, t}}{P_{t}}\right)^{-\epsilon} c_{t}+a_{k}\left(i_{x, t}+i_{n, t}+A C_{x, t}+A C_{n, t}\right)+a_{z} \mathbb{I}_{z, t} .
$$

The first term of the right-hand side of (32) is the demand for non-traded consumer goods, while the second and third terms link public and private investment to orders for new capital goods.

Finally, aggregating across consumers and adding the public and private sector budget constraints produce the accounting identity that growth in the country's net foreign debt equals the difference between national spending and national income:

$$
\begin{aligned}
d_{t}-d_{t-1}+d_{c, t}-d_{c, t-1}+b_{t}^{*}-b_{t-1}^{*}= & \frac{r_{d}-g}{1+g} d_{t-1}+\frac{r_{d c, t-1}-g}{1+g} d_{c, t-1}+\frac{r_{t-1}^{*}-g}{1+g} b_{t-1}^{*} \\
& +\mathcal{P}_{t}+P_{z, t} \mathbb{I}_{z, t}+P_{k, t}\left(i_{x, t}+i_{n, t}+A C_{x, t}+A C_{n, t}\right) \\
& +P_{t} c_{t}-P_{n, t} q_{n, t}-P_{x, t} q_{x, t}-\mathcal{R}_{t}-\mathcal{G}_{t}-\mathcal{N}_{t} .
\end{aligned}
$$

Equation (33) includes extra terms that reflect the impact of trend growth on real interest costs and the contributions of remittances, grants, and natural resource related foreign transfers to gross income. The textbook identity emerges when $g=\mathcal{R}_{t}=\mathcal{G}_{t}=\mathcal{N}_{t}=0$.

\section{Calibration of the Model}

Calibration of the model requires data on cost shares, elasticities of substitution, consumption shares, depreciation rates, sector shares in GDP, tax rates, debt stocks, and the return on infrastructure at the benchmark equilibrium. Once values are set for these parameters, all other variables that enter the model can be tied down by budget constraints, the first-order conditions associated with the solution to the private agents' optimization problems, and various adding-up constraints.

The values in Table 1 are based on a mixture of data and guesstimates. We assume that $P_{n, o}=$ $P_{x, o}=P_{m, o}=P_{m m, o}=w_{o}=P_{o}=1$ and discuss below the rationale for the value assigned to each parameter and the problems that arose in calibrating certain parts of the model: 
- The distribution parameters $\left(\rho_{n}, \rho_{x}, \rho_{m}\right)$. In the base case, we pick $\rho_{n}$ and $\rho_{m}$ so that, the share of non-tradables in GDP is about 50\% and the share of imports in GDP is around 45\%, which correspond to average shares of non-tradables and imports for LICs during 1998-2008 using WEO data. This gives us $\rho_{n}=0.43$ and $\rho_{m}=0.37$. Then $\rho_{x}$ is calculated as $\rho_{x}=1-\rho_{n}-\rho_{m}$.

- Intertemporal elasticity of substitution $(\tau)$. According to Agenor and Montiel (1999), most estimates of $\tau$ for LDCs lie between 0.10 and 0.50 . The value in the base case, 0.34 , equals the average estimate for LICs in Ogaki et al. (1996).

- Elasticity of substitution in consumption $(\epsilon)$. We fix $\epsilon$ at 0.50 as estimates of compensated elasticities of demand tend to be small at high levels of aggregation, especially when food claims a large share of total consumption. ${ }^{25}$

- Capital's share in value added $\left(\alpha_{n}, \alpha_{x}\right)$. Data on factor shares may be found in social accounting matrices assembled by the Global Trade Analysis Project (GTAP) and the International Food Policy Research Institute (IFPRI). The GTAP5 database for SSA suggests a capital share of $55-60 \%$ in the non-tradables sector and $35-40 \%$ in the tradables sector. ${ }^{26}$ The data in Thurlow et al. (2004) and Perrault et al. (2010) suggest similar numbers. ${ }^{27}$ Accordingly, we set $\alpha_{n}=0.55$ and $\alpha_{x}=0.40$.

- Learning externalities $\left(\xi_{x}, \xi_{n}, \sigma_{x}, \sigma_{n}\right)$. The base case does not incorporate learning externalities. In alternative runs that allow for learning effects, $\xi_{x}$ and $\xi_{n}$ are set to 0.08 so that the social return to capital in the traded sector is about $30 \%$ higher than the private return. ${ }^{28}$

- Cost share of non-traded inputs in the production of capital goods $\left(\alpha_{k}, \alpha_{z}\right)$. Data on the ratio of imported machinery and equipment to aggregate investment indicate that $\alpha_{k}$ and $\alpha_{z}$ are around 0.5 in SSA. One-half is also the guesstimate used by the IMF (2007a) in its analysis of scaling up public investment in Nigeria.

- Elasticities of sectoral output with respect to the stock of infrastructure $\left(\psi_{x}, \psi_{n}\right)$. The ratio $\psi_{x} / \psi_{n}$ is set independently. This ratio and other values assigned elsewhere in calibrating the modelmost notably, the return on infrastructure - pin down $\psi_{n}$ and $\psi_{x} \cdot{ }^{29}$ We assume $\psi_{x} / \psi_{n}=1$ in all runs and obtain that $\psi_{n}=0.17$.

- Depreciation rate $(\delta)$. There is little hard data on depreciation rates in LICs. Our choice of $5 \%$ is in line with estimates for developed countries.

\footnotetext{
${ }^{25}$ See Lluch et al. (1977, chapter 3), Deaton and Muellbauer (1980, p.71), Blundell (1988, p.35), and Blundell et al. (1993, Table 3b).

${ }^{26}$ The nontradables sector comprises trade and transport, private services, dwellings, and construction. The tradables sector consists of agriculture and manufacturing.

${ }^{27}$ The average factor shares cited here conceal tremendous variation. For example, the value added share of capital in the services sector is $59 \%$ in Zambia but only $27 \%$ in Malawi. See Thurlow et al. (2004) and Thurlow et al. (2008).

${ }^{28}$ The net social return to capital, evaluated at a steady state is $(r+\delta)\left(1+\xi_{j} / \alpha_{j}\right)-\delta$. To set $\xi_{j}$ so that the social return is $30 \%$ above the private return, solve $(r+\delta)\left(1+\xi_{j} / \alpha_{j}\right)-\delta=(1.30) r$ for $\xi_{j}$.

${ }^{29} \psi_{n}$ and $\psi_{x}$ are linked to other parameters and variables through $R_{z}=\left(\psi_{n} V A_{n}+\psi_{x} V A_{x}\right)(\delta+g) / i z_{y}$, where $R_{z}=R+\delta$ is the gross return on infrastructure, $V A_{j}$ is the share of sector j production in GDP, and $i z_{y}$ is the ratio of infrastructure investment to GDP.
} 
Table 1

Base Case Calibration

\begin{tabular}{|c|c|c|}
\hline Parameter & Value & Definition \\
\hline$\rho_{n}$ & 0.43 & 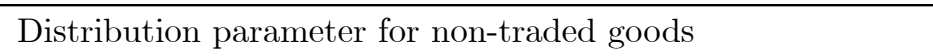 \\
\hline$\rho_{m}$ & 0.37 & Distribution parameter for traded goods \\
\hline$\tau$ & 0.34 & Intertemporal elasticity of substitution \\
\hline$\epsilon$ & 0.50 & Intratemporal elasticity of substitution across goods \\
\hline$\alpha_{x}$ & 0.40 & Capital's share in value added in the traded sector \\
\hline$\alpha_{n}$ & 0.55 & Capital's share in value added in the non-traded sector \\
\hline$\xi_{x}, \xi_{n}$ & 0.00 & Capital learning externalities \\
\hline$\sigma_{x}, \sigma_{n}$ & 0.00 & Sectoral output learning externalities \\
\hline$\alpha_{k}, \alpha_{z}$ & 0.50 & Cost share of non-traded inputs in the production of capital \\
\hline$\psi_{x}, \psi_{n}$ & 0.17 & Elasticities of sectoral output with respect to infrastructure \\
\hline$\delta$ & 0.05 & Depreciation rate \\
\hline$v$ & 6.41 & Capital adjustment cost parameter \\
\hline$\mu$ & 0.05 & User fees parameter for infrastructure services \\
\hline$g$ & 0.015 & Trend growth rate \\
\hline$r_{o}$ & 0.10 & Initial real interest rate on domestic debt \\
\hline$r_{o}^{*}$ & 0.10 & Initial real interest rate on private external debt \\
\hline$r^{f}$ & 0.04 & Real risk-free foreign interest rate \\
\hline$r_{d}$ & 0.00 & Real interest rate on concessional loans \\
\hline$r_{d c, o}$ & 0.06 & Initial real interest rate on public commercial loans \\
\hline$\eta$ & 1.00 & The portfolio adjustment costs parameter \\
\hline$\eta_{g}$ & 0.00 & Public debt risk premium parameter \\
\hline $\mathfrak{u}$ & 0.04 & Private debt risk premium \\
\hline$v_{g}$ & 0.02 & Public debt risk premium \\
\hline$R_{o}$ & 0.25 & Initial return on infrastructure \\
\hline$b_{o}$ & 0.20 & Initial public domestic debt to GDP ratio \\
\hline$d_{o}$ & 0.50 & Initial public concessional debt to GDP ratio \\
\hline$d_{c, o}$ & 0.00 & Initial public external commercial debt to GDP ratio \\
\hline$b_{o}^{*}$ & 0.00 & Initial private external debt to GDP ratio \\
\hline $\mathcal{G}_{O}$ & 0.05 & Grants to GDP ratio \\
\hline $\mathcal{R}_{o}$ & 0.04 & Remittances to GDP ratio \\
\hline $\mathcal{N}_{o}$ & 0.00 & Natural Resource Revenues to GDP ratio \\
\hline$i_{z, o}$ & 0.06 & Initial ratio of infrastructure investment to GDP \\
\hline $\bar{s}, s$ & 0.60 & Efficiency of public investment \\
\hline$\phi$ & 0.00 & Absorptive capacity parameter \\
\hline$h_{o}$ & 0.15 & Initial consumption VAT \\
\hline $\mathcal{T}_{o}$ & 11.93 & Initial transfers to GDP ratio \\
\hline$\lambda$ & 0.00 & Division of fiscal adjustment parameter \\
\hline$\lambda_{1}, \lambda_{3}$ & 0.25 & Fiscal reaction parameters (policy instrument terms) \\
\hline$\lambda_{2}, \lambda_{4}$ & 0.02 & Fiscal reaction parameters (debt terms) \\
\hline$a$ & 1.50 & Labor ratio of non-savers to savers \\
\hline
\end{tabular}

Note: See the calibration discussion in the main text. 
- The capital adjustment costs parameter $(v)$. Evaluated at the initial equilibrium, this parameter is related to $\Omega$, the elasticity of investment with respect to Tobin's q, according to $\Omega=1 /(\delta+$ $g) v{ }^{30}$ There are no reliable estimates of this elasticity for LICs. The assigned value, 2 , is at the high end of estimates for developed countries. This implies $v=6.41$. The results do not change substantively when $\Omega$ equals 1 or 10 .

- The user fees for infrastructure services $(\mu)$. The user fee for infrastructure services is a fixed multiple/fraction $f$ of recurrent costs $\mu=f \delta P_{z o}$. Fuel taxes, which are earmarked for road maintenance and construction, electricity tariffs, and user charges for water and sanitation are low but not trivial in LICs. According to Briceño-Garmendia et al. (2008), on average, user fees recoup 50\% of recurrent costs in SSA. Again, however, there is considerable variationZambia's average electricity tariff was three cents per $\mathrm{kWH}$ in 2008. We decided therefore to let $f$ vary from 0.20 to unity, with $f=0.50$ in the base case. Since in the baseline calibration $P_{z o}=\frac{1}{1-\alpha_{z}}=2$ and $\delta=0.05$, then $\mu=0.05$.

- Trend growth rate $(g)$. The trend growth rate of 1.5\% equals the 1990-2008 per capita growth rate for SSA reported in African Development Indicators.

- The real interest rate on domestic bonds $(r)$, the real return on private capital, and the real interest rate on external private debt $\left(r^{*}\right)$. Across steady states, the real interest rate on domestic debt and the real return on private capital equal $(1+\varrho)(1+g)^{\tau}-1$, where $\varrho$ is the subjective discount rate. We choose $\varrho$ jointly with $\tau$ and $g$ so that the domestic real interest rate is $10 \%$ at the initial equilibrium. This is consistent with the data for SSA in Fedelino and Kudina (2003), with the estimated return on private capital in Dalgaard and Hansen (2005), and with the stylized fact that domestic debt in low- and middle-income countries is usually more expensive than external commercial debt. There is tremendous variation in real interest rates across countries and time periods, however. Note that at the steady state equation (14) implies that the interest rate that the private sector pays on foreign debt must satisfy $r^{*}=r$. So for the base case we also have $r^{*}=0.10$.

- The risk-free foreign real interest rate $\left(r^{f}\right)$. We fix $r^{f}$ at $4 \%$, the approximate average of the historical real returns on stocks and 3-10 year T bills in the United States.

- Real interest rates on concessional and non-concessional loans $\left(r_{d}, r_{d c, o}\right)$. Ghana paid 8.7\% on the $\$ 750 \mathrm{mn}$. Eurobond it floated in 2007. This is slightly above Gueye and Sy's (2010) estimate of the average interest rate SSA pays $(8.55 \%)$ on debt raised in external capital markets, excluding Seychelles and South Africa. The IMF-WB's DSAs show an average interest rate of $2.3 \%$ on concessional loans taken out by LICs in 2009-2010. Assuming $2.5 \%$ inflation in world prices of traded goods, the corresponding (initial) real rates in dollars are about $6 \%$ for commercial debt and $0 \%$ for concessional debt. The latter is assumed to be constant through the analysis.

\footnotetext{
${ }^{30}$ In each sector $j$, the first-order condition for investment reads $\left[1+v\left(i_{j, t} / k_{j, t-1}-\delta-g\right)\right] \varpi_{t} P_{k, t}=\varsigma_{t}$, where $\varpi_{t}$ and $\varsigma_{t}$ are the multipliers associated with the budget constraint and the law of motion for the capital stock. Since $\frac{\varsigma_{t}}{\varpi_{t}}$ is the shadow price of capital measured in dollars, $\frac{\varsigma_{t}}{\varpi_{t}} P_{k}$ is effectively Tobin's $q$, the ratio of the demand price to the supply price of capital. Adopting this notation, we have that at a stationary equilibrium $v(\delta+g) \frac{\bar{q}}{\bar{q}}=1$. Define $\Omega \equiv \frac{\bar{\imath}}{\bar{q}}$ to be the q-elasticity of investment spending. Then $v=1 /(\delta+g) \Omega$.
} 
- The portfolio adjustment costs parameter $(\eta)$ and the private and public debt risk premia parameters $\left(\mathfrak{u}, v_{g}, \eta_{g}\right)$. The parameter $\eta$ controls the degree of openness of the capital account. We set $\eta=1$, in the base case, to capture the fact that the private sector has limited access to international capital markets. We assume that the public risk premium is constant-i.e., we set $\eta_{g}=0$ in equation (22) - and calibrate it as the difference between the interest rate on public commercial debt and the risk-free foreign interest rate. So, at the initial steady state equilibrium, $v_{g}=r_{d c}-r^{f}=0.02$. The constant private risk premium is set as the difference between the domestic interest rate and the interest rate on public commercial debt. Therefore $\mathfrak{u}=r^{*}-r_{d c}=0.04$.

- Return on infrastructure $\left(R_{o}\right) \cdot{ }^{31}$ Estimates of the return on infrastructure are all over the map, but the weight of the evidence in both micro and macro studies points to a high average return. The median rate of return on World Bank projects circa 2001 was $20 \%$ in SSA and 15-29\% for various sub-categories of infrastructure investment. Foster and Briceño-Garmendia (2010) estimate returns for electricity, water and sanitation, irrigation, and roads range from $17 \%$ to 24\%. Similarly, the macro-based estimates in Dalgaard and Hansen (2005) cluster between 15\% and $30 \%$ for a wide array of different estimators. Hulten et al. (2006), Escribano et al. (2008), Calderón et al. (2009), and Calderón and Servén (2010) supply additional evidence of high returns. $^{32}$ All of this adds up to a presumption that high returns are the norm. We consider a high-return scenario as the base case by setting $R_{o}=0.25$, at the initial steady state. ${ }^{33}$

- Domestic debt $\left(b_{o}\right)$. Different datasets give different numbers for the ratio of domestic debt to GDP in LICs. We settled on $20 \%$ by averaging the figures reported in IMF(2009a), Panizza (2008), and Arnone and Presbitero (2010).

- Private foreign debt and public external debt $\left(b_{o}^{*}, d_{o}, d_{c, o}\right)$. We set concessional external debt equal to $50 \%$ of GDP at the initial equilibrium, given that the ratio of total public debt to GDP and the share of concessional loans in total debt were about $70 \%$ and $69 \%$, respectively, for LICs during 2007-2008. ${ }^{34}$ As little is known about the likely value of private foreign debt (or assets) in LICs, we set $b_{o}^{*}=0$ for the base case. We also assume that initially the economy has no access to external commercial loans implying that $d_{c, o}=0$.

- Remittances, Grants, and Natural Resource Revenues $\left(\mathcal{R}_{o}, \mathcal{G}_{o}, \mathcal{N}_{o}\right)$. For the base case, remittances and grants are assumed to be $5 \%$ and $4 \%$ of GDP at their initial equilibrium, respectively. These are in line with averages for LICs in the last decade. For the baseline calibration we assume that the economy is not endowed with natural resources.

- Initial ratio of infrastructure investment to GDP $\left(\frac{i_{z, o}}{y_{o}}\right)$. We set the initial infrastructure investment to be equal to $6 \%$ of GDP. This initial figure includes the net investment associated with

\footnotetext{
${ }^{31}$ The production function parameters $\psi_{x}$ and $\psi_{n}$ that govern $R_{o}$ are deduced from the calibration of $R_{o}$, given the rest of the calibration.

${ }^{32}$ Some growth regressions suggest low or insignificant returns, but these are dominated by studies that use cumulative public investment instead of physical indicators to measure the stock of instructure.

${ }^{33}$ Thirty percent may raise some eyebrows, but it is not as big as some of the numbers thrown around in the literature and in policy work. See for instance the scaling-up exercise in Box 4.1 in Barkbu et al. (2008) and Gupta, Powell, and Yang (2006).

${ }^{34}$ See IMF (2009a) and IMF staff calculations.
} 
trend growth and the outlays on operations and maintenance $(\mathrm{O}+\mathrm{M})$ - which average about $3.4 \%$ of GDP for LICs in SSA. ${ }^{35}$ This figure is close to the average for LICs in SSA, which in 2008 corresponded to $6.09 \%$, as suggested by Briceño-Garmendia et al. (2008).

- Efficiency of public investment $(s, \bar{s})$ and the absorptive capacity parameter $(\phi) .{ }^{36}$ The base case assumes that investment is somewhat efficient $(\bar{s}=0.60$ and $s=0.60)$ and that scaling up does not strain absorptive capacity $(\phi=0$ and $\bar{s}=s)$. Motivated by the findings in Hulten (1996), Pritchett (2000), and Foster and Briceño-Garmendia (2010), we also investigate scenarios in which the scaling up is associated with extreme inefficiency $(s=0.2)$ and a tight absorptive capacity constraint $(\phi=5) .{ }^{37}$

- Consumption VAT $\left(h_{o}\right)$. The consumption VAT in the model proxies for the average indirect tax rate. Our rate of $15 \%$, at the initial steady state. ${ }^{38}$ This is comparable to the average VAT of LICs, which using 2005-06 data by the International Bureau of Fiscal Documentation is estimated to be close to $15.8 \%$.

- Net Transfers $\left(\mathcal{T}_{o}\right)$. At the initial steady state, transfers ensure that the budget constraint of the government holds. Given the other parameters we obtain $\mathcal{T}_{o}=11.93$ percent of GDP. Given the definition of the other fiscal variables, this concept of transfers includes other taxes different from VAT as well as non-capital expenditures such as public wages.

- Division of fiscal adjustment between expenditure cuts and tax increases ( $\lambda$ ). Across steady states, we assume that only taxes share the burden of fiscal adjustment $(\lambda=0)$.

- Policy reaction parameters $\left(\lambda_{1}, \lambda_{2}, \lambda_{3}, \lambda_{4}\right)$. There are no estimates of these parameters for LICs. For the scenarios that allow commercial debt accumulation or domestic debt accumulation we set $\lambda_{1}=\lambda_{3}=0.25$ and $\lambda_{2}=\lambda_{4}=0.02$. We also study the implications of lowering $\lambda_{1}$.

- Ratio of labor supply of non-savers to labor supply of savers $(a)$. We set $a=1.5$, so $60 \%$ percent of the consumers are non-savers. This is broadly in line with survey findings in LICs.

\footnotetext{
${ }^{35}$ But true $\mathrm{O}+\mathrm{M}$ costs are probably higher, as argued by Briceño-Garmendia et al. (2008). Because of underspending on $\mathrm{O}+\mathrm{M}, 30 \%$ of Africa's infrastructure assets are in need of rehabilitation.

${ }^{36}$ Appendix A describes how calibration of $s$ and $\bar{s}$ interact with that of $R_{o}$ and the production function parameters $\psi_{x}$ and $\psi_{n}$. The bottom line is that the operator needs to be thoughtful when calibrating efficiency, particularly in considering what it might imply for the marginal product of effective capital. A change in the calibration of the efficiency $s$ has two different interpretations: (i) as a level change that applies to the past and the future, as when comparing two countries at a point in time. In this case, $\bar{s}$ should in principle change as well, but a change in $\bar{s}$ is unnecessary, because any effect of changing $\bar{s}$ is undone by the change in $\psi_{x}$ and $\psi_{n}$ required to preserve the value of $R_{o}$; or (ii) as a change that applies to future investment but not the past, as for example because of an improvement in public financial management. It is up to the operator to decide which applies and whether other adjustments to the calibration are necessary in light of that interpretation.

${ }^{37}$ Pritchett's estimates of $s$ range from 0.08 to 0.49 for SSA and from 0.09 to 0.54 for South Asia. In Africa, large cost overruns stemming from planning/coordination/management problems and low capital budget execution ratios (average $=66 \%$ ) suggest that absorptive capacity may be a binding constraint in many countries. See Foster and Briceño-Garmendia (2010).

${ }^{38}$ For 2003-2006, consumption, indirect taxes, and trade taxes averaged $81 \%, 9.6 \%$, and $4.6 \%$ of GDP, respectively. If duties on consumer imports accounted for half of trade taxes, then the average consumption tax was $14.7 \%$. (Data from IMF, 2007b). Ideally this rate will also reflect VAT productivity adjustments.
} 
The public investment scaling-up scenario we study is exogenous and front loaded. Concessional borrowing and an increase in grants, which are also exogenous, help finance this scaling up.

The time lines for the infrastructure investment surge (valued at the initial price level $P_{z, o}=2$ ), concessional borrowing, and the increase in grants, as percentage of initial GDP $\left(y_{o}=100\right)$, are shown in Table 2. The time lines are hump-shaped. In year 1 public investment is at $6 \%$ of GDP and there is no increase. Then the scaling up of this investment jumps to $5 \%$ of initial GDP in year 2 , rises to $7 \%$ in years 3 and 4 , and tapers off gradually to its permanent level of $3 \%$ of initial GDP. Net concessional loans, on the other hand, increase by $4 \%$ of GDP in year 2, go slightly up to $5 \%$ of initial GDP in year 3 and then decline gradually until year $9 .{ }^{39}$ From year 10 to year 28 , the country repays these loans $(-1.01 \%$ of initial GDP). The increase in grants $\mathcal{G}$ corresponds to $0.4 \%$ of initial GDP from year 2 to year 9 , and declines to $0.2 \%$ before dying off by year 32 . Concessional borrowing and the increase in grants will only cover about $50 \%$ of the investment surge during the first 8 years of the scaling up. The rest will require some fiscal adjustment and, potentially, other sources of financing such as external commercial or domestic borrowing.

Table 2

Public Investment Scaling Up, Concessional Borrowing, and Grants

\begin{tabular}{ccccccccccccc}
\hline \hline Year & 1 & 2 & 3 & 4 & 5 & 6 & 7 & 8 & 9 & $10 \ldots$ & $29 \ldots$ & $32 \ldots$ \\
\hline \hline$\frac{P_{z, o}\left(i_{z, t}-i_{z, o}\right)}{y_{o}}$ & 0.0 & 5.0 & 7.0 & 7.0 & 6.6 & 5.8 & 5.0 & 4.4 & 4.0 & $3.0 \ldots$ & $3.0 \ldots$ & 3.0 \\
$\frac{\text { Net Loans shock }}{y_{o}}$ & 0.0 & 4.0 & 5.0 & 4.0 & 3.0 & 2.0 & 1.0 & 0.8 & 0.5 & $-1.01 \ldots$ & $0.0 \ldots$ & 0.0 \\
$\frac{\mathcal{G}_{t}-\mathcal{G}_{o}}{y_{o}}$ & 0.0 & 0.4 & 0.4 & 0.4 & 0.4 & 0.4 & 0.4 & 0.4 & 0.4 & $0.2 \ldots$ & $0.2 \ldots$ & 0.0
\end{tabular}

Note: figures are in percent of initial GDP $\left(y_{o}=100\right)$.

\section{The Long-Run Outcome}

In this section, we use a mix of analytical and numerical methods to demonstrate that in the long run (i) infrastructure and private capital are strong complements and (ii) increases in infrastructure investment can be self-financing, depending on structural conditions of the economy.

\footnotetext{
${ }^{39}$ The repayment period is leisurely stretched out over 27 years, after 8 years of grace period. These correspond roughly to the average maturity and grace-period years for new concessional loans to LICs in 2009-2010, based on available IMFWB's DSAs. We assume that the country contracts a concessional loan of $20.25 \%$ of initial GDP in year 2 , with the previously described disbursements. Then we apply an equal principal payment formula, together with these grace and maturity periods and an interest rate of $0 \%$, to obtain the repayment profile. The grant element of this loan is about $62 \%$.
} 


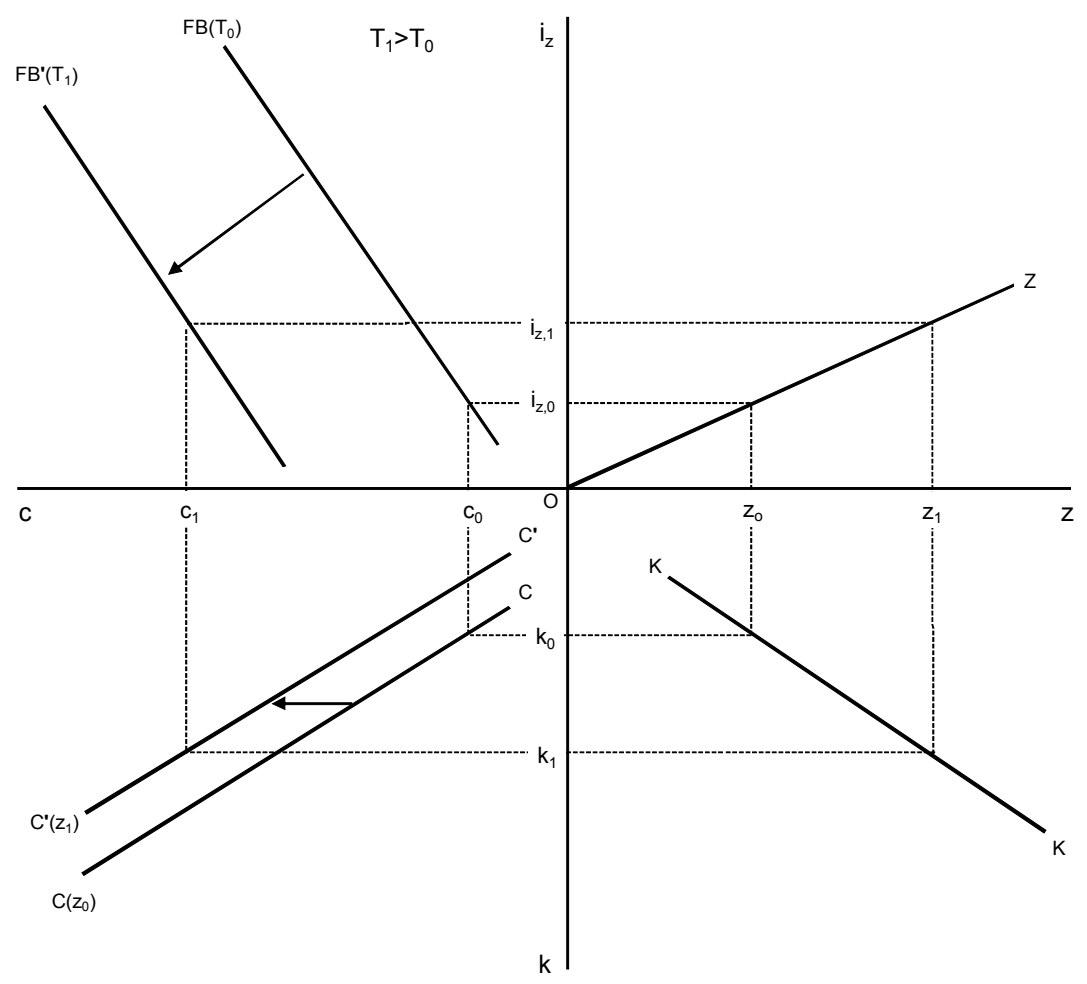

Figure 1: The Long-run Outcome in the Simplified Model.

\section{A. Insights From a Simplified Model}

Although the model of Section II has many moving parts, it is not a black box. To highlight the key interactions that drive the long-run (steady-state) outcome, consider a stripped-down model that ignores trend growth, non-traded goods, foreign traded goods, private capital flows, remittances, grants, natural resource revenues, public sector debt and efficiency and absorptive capacity issues (so $s=\bar{s}=1$ and $\phi=0$ ). For notational simplicity we ignore the upper bars on the variables, which we used before to denote steady-state values. With these elements gone, the steady-state equilibrium simplifies to

$$
\begin{gathered}
q=a z^{\psi} k^{\xi+\alpha} L^{1-\alpha}, \\
r+\delta=\alpha a z^{\psi} k^{\xi+\alpha-1} L^{1-\alpha}, \\
i_{z}=\delta z \\
h c+\mu z=\delta z+\mathcal{T},
\end{gathered}
$$

and

$$
c=q-\delta(k+z)
$$

five equations that can be solved for $q, k, z, c$ and either $\mathcal{T}$ or $h$ as a function of $i_{z}$. Equation (34) is the production function and equations (35)-(38) are the steady-state versions of equations (8), (18),(21), and (33) in Section II. 
Figure 1 depicts the steady-state equilibrium when transfer payments adjust to satisfy the government budget constraint, but similar results obtain if all the fiscal adjustment falls on taxes. The ray $\mathrm{OZ}$ in the first quadrant relates $z$ to $i_{z}$. For the results that follow, it is important to note the obvious: the slope of OZ is quite flat because comparatively small increases in $i_{z}$ map into very large increases in $z$ over the long run $\left(d z=d i_{z} / \delta\right)$.

Proceeding south, the KK schedule in the fourth quadrant shows how the equilibrium private capital stock depends on the stock of infrastructure. From (35),

$$
d k=\left(\frac{k}{z}\right)\left(\frac{\psi}{1-\xi-\alpha}\right) d z>0 .
$$

Substitute $k=\frac{\alpha q}{r+\delta}$ and $z=\frac{\psi q}{q_{z}}=\frac{\psi q}{R+\delta}$ into (39), where $R=q_{z}-\delta$ is the net return to infrastructure and $q_{z}=\frac{\psi q}{z}$ is the marginal product of infrastructure. After canceling terms, we have

$$
\left.\frac{d k}{d z}\right|_{K K}=\left(\frac{R+\delta}{r+\delta}\right)\left(\frac{\alpha}{1-\xi-\alpha}\right)
$$

Since we have assumed a Cobb-Douglas technology, growth in the stock of infrastructure stimulates private investment by increasing the marginal product of capital. Equation (40) tells us, in addition, that the long-run crowding-in effect may be quantitatively large. The ratio of the gross return on infrastructure to the gross return on private capital, $\frac{R+\delta}{r+\delta}$, multiplies a term that lies somewhere between 0.49 and 1.83 , if $\alpha \in[0.33,0.55]$ and $\xi \in[0,0.15]$. Thus, if empirical estimates are right and the mean return on infrastructure is much higher than the mean return on private capital, then the long-run crowding-in coefficient can approach or exceed two. Suppose, for example, that $r=0.10$, $R=0.25, \delta=0.05$, and $\alpha=0.40$ as there is only one domestic traded good. The crowding-in coefficient $\frac{d k}{d z}$ then ranges from about 1.33 to 1.78 when $\xi \in[0,0.15]$. Productive infrastructure and private capital are very strong complements in the long run. This, however, depends on structural conditions of the economy. As we will see below, public investment inefficiencies and absorptive capacity constraints, among others, can lower the crowding in.

The schedules in the second and third quadrants connect the increases in the stocks of infrastructure and private capital to consumption, tax revenue, and the change in transfers needed to balance the fiscal budget. CC relates $c$ to $k$ for given $z$, while FB depicts the locus in the $c-i_{z}$ plane for which revenue equals government expenditure. The slope of CC equals $(r+\delta)(1+\xi / \alpha)-\delta$, the net social marginal product of capital. The FB schedule

$$
\left.i_{z}\right|_{F B}=\frac{h c-\mathcal{T}}{1-\frac{\mu}{\delta}}
$$

has a horizontal intercept at $c=\frac{\mathcal{T}}{h}$ and a positive slope that rises from $h$ at $\mu=0$ to infinity at $\mu=\delta$.

When $z$ increases, the CC schedule shifts horizontally to the left by $R\left(z_{1}-z_{o}\right)$. Crowding-in of private capital increases consumption another $[(\rho+\delta)(1+\xi / \alpha)-\delta]\left(k_{1}-k_{o}\right)$. Expressed relative to the policy instrument $i_{z}$, the combined effect is

$$
d c=\left[\left(\xi+\frac{r \alpha}{r+\alpha}\right) \frac{R+\delta}{1-\xi-\alpha}+R\right] \frac{d i_{z}}{\delta} .
$$


Comparing the increase in consumption taxes and user fees $\left(h d c+\mu d z=h d c+\frac{\mu}{\delta} d i_{z}\right)$ to the increase in investment determines whether the FB schedule shifts left or right. In Figure 1 the revenue gain pays for the increase in investment and leaves something left over to finance higher transfer payments. This case occurs when

$$
R>\frac{\delta\left(1+h-\frac{\mu}{\delta}\right)(1-\xi-\alpha)}{h\left(1-\frac{\alpha \delta}{r+\delta}\right)}-\delta .
$$

The crucial implication of (41) is that $R$ does not have to be unusually high for the increase in infrastructure investment to be self-financing. Consider the base case values of Table 1 but bear in mind that in this simplified model $\alpha=0.40$ (since there is only one domestic traded good) and $\mu=0.025$ (since $\mu=\delta f$ and $f=0.50$ ). In this case, the borderline value of $R$ is a modest $10 \%$. Even with $\mu=0$, however, (41) holds for $R>21.5 \%$. This is high but well within the range of empirical estimates. Moreover, note that this borderline value decreases with the externalities $\xi$.

\section{B. Numerical Solutions}

Table 3 summarizes the long-run effects of a permanent increase in public investment equal to $3 \%$ of initial GDP using the full model. Consider first the base case. Transfers are kept constant, by assumption, while taxes require a small adjustment from $15 \%$ to $16.3 \%$. As predicted by the

simplified model, the crowding-in coefficient, calculated as $\frac{\Delta k}{\Delta z}$, exceeds unity. Consequently there are some gains in the economy. Real output, real wages, and private capital increase by more than $13 \%$ while consumption rises by $9.3 \%$. Sectoral outputs also move up, and there is a permanent real depreciation of $1.9 \%$. Our base case calibration then delivers a positive scenario, to some extent. But even with a rate of return on public capital of $25 \%$ the public investment does not pay for itself. The average tax rate is quite low, and most of the benefits accrue to the private sector are not sufficient to cover the recurrent costs.

The long-run impact of the public investment scaling up depends on the structural conditions of the economy. To see this, consider scenario 1 of Table 3 . This scenario is very optimistic. The return on capital is $35 \%$, user fees recoup all recurrent costs-i.e., $f=1$ implying that $\mu=f \delta P_{z o}=0.1$ - the public investment surge is fully efficient $s=1$, and there are some positive externalities $\xi=0.08$, which imply a social return to capital in the traded sector that is $30 \%$ higher than the private return. With these conditions, the scaling up turns out to be more than self-financing and produces striking benefits in the real economy. Taxes decline to $12.3 \%$ in the long run, while real GDP, wages, and private capital expand by about $33-35 \%$, as the crowding-in coefficient is above 2. Furthermore, consumption jumps by $29.3 \%$.

We issue two caveats.

First, it is also possible to recreate very troublesome scenarios under weak structural conditions that may characterize some LICs. Scenario 2 in Table 3 is an example. This scenario features a low return on public capital $R=0.10$, a deficient collection rate of user fees of $20 \%$ of recurrent costsi.e., $f=0.2$ implying that $\mu=f \delta P_{z o}=0.02$ - and an insignificant efficiency of additional public 
investment $s=0.2$. As a result, taxes have to adjust permanently to $18.7 \%$ and consumption falls by $1.2 \%{ }^{40}$ In addition, real GDP and private capital have disappointing increases of about $2.5 \%$, despite the large increase in public investment. All of this is consistent with a crowding-in coefficient that is below 1.

Table 3

Long-run Effects of Scaling Up Public Investment by 3 Percent of Initial GDP

\begin{tabular}{l|c|c|c}
\hline \hline & Base Case & Scenario 1 & Scenario 2 \\
\cline { 2 - 4 } & $\begin{array}{c}R=0.25, \mu=0.06, \\
s=0.60, \text { and } \xi=0\end{array}$ & $\begin{array}{c}R=0.35, \mu=0.1, \\
s=1, \text { and } \xi=0.08\end{array}$ & $\begin{array}{c}R=0.10, \mu=0.02, \\
s=0.2, \text { and } \xi=0\end{array}$ \\
\hline \hline & & & \\
Taxes $h$ & 16.29 & 12.26 & 18.73 \\
CIC $\Delta\left(k_{x}+k_{n}\right) / \Delta z^{e}$ & 1.51 & 2.31 & 0.85 \\
Public Effective Capital $z^{e}$ & 50.00 & 83.33 & 16.67 \\
Private Capital $k_{x}+k_{n}$ & 13.23 & 33.70 & 2.49 \\
Real GDP $y^{r}$ & 13.45 & 34.31 & 2.48 \\
Real Wages $w / P$ & 13.53 & 34.66 & 2.44 \\
Consumption $c$ & 9.29 & 29.30 & -1.24 \\
Traded Output $q_{x}$ & 13.83 & 35.99 & 2.21 \\
Non-Traded Output $q_{n}$ & 13.04 & 32.57 & 2.75 \\
Real Exchange Rate $p_{n}$ & -1.90 & -3.90 & -0.36 \\
& & & \\
\hline
\end{tabular}

Note: The effects are measured as the percentage change between the steady states, except

for taxes and the crowding-in coefficient (CIC). Fiscal adjustment is assumed to fall exclusively on taxes, so transfers are kept constant.

The second caveat pertains to difficulties that may arise on the transition path. As we will show in the next section, even when the long run looks good, medium-run tax increases appear to be unavoidable. Non-concessional borrowing can smooth away difficult fiscal adjustments that threaten to undermine support for the investment program. But if the capacity for fiscal adjustment is too limited and the government borrows too much in the short/medium run, there is a risk that future revenue gains will not arrive fast enough to prevent explosive growth of the debt. Therefore, the viability of the borrowing-for-development strategy depends not only on the structural conditions of the economy and the long-run outcome, but also on whether policy makers can solve the problem of how to get from here to there.

\footnotetext{
${ }^{40}$ Note that the adjustment in taxes would be smaller if government transfers were cut. But this is not an easy task when public sector employees are pressing for wage increases that match the increase in the private sector wages.
} 


\section{The Medium-Term Fiscal and Macroeconomic Adjustments Under Different Financing Schemes}

\section{A. Unconstrained Tax Adjustment}

There are a variety of ways to finance a large increase in public investment. We start by analyzing the case in which, given the public investment surge and the path for concessional borrowing and grants, taxes and/or transfers adjust continuously and freely to satisfy the budget constraint of the government. This provides the counterfactual for the analysis of riskier schemes that supplement concessional borrowing with domestic or external commercial loans.

For now, we assume the government is unable or unwilling to take out non-concessional debt. Commercial and domestic debt thus stay at their initial steady-state levels; so $d_{c, t}=\bar{d}_{c}=d_{c, o}$ and $b_{t}=\bar{b}=b_{o}$. Taxes and transfers adjust continuously and without bounds. To capture this we set $h^{u} \rightarrow \infty, \mathcal{T}^{l} \rightarrow \infty, \lambda_{1}=\lambda_{3}=1$ and $\lambda_{2}=\lambda_{4}=0$ in equations (27)-(30) and combine them with (25) and (26) to obtain

$$
h_{t}=h_{t}^{\text {target }} \quad \text { and } \quad \mathcal{T}_{t}=\mathcal{T}_{t}^{\text {target }}
$$

To fix ideas and simplify the analysis, in the experiments below we assume the burden of fiscal adjustment falls exclusively on taxes. In other words, we set $\lambda=0$. This implies that transfers are kept constant at their initial level $\mathcal{T}_{t}=\mathcal{T}_{t}^{\text {target }}=\mathcal{T}_{o}$, while taxes follow the path $h_{t}=h_{t}^{\text {target }}$, which, given $\lambda_{1}=1$ and $\lambda_{2}=0$, ensures that taxes always adjust to satisfy the government budget constraint.

\section{A.1. The Base Case}

The medium-run dynamics presented in Figure 2 are discouraging. ${ }^{41}$ Since cumulative borrowing and grants in years 2-9 equals about $50 \%$ of cumulative net investment, the fiscal adjustment has to be demanding. The VAT rises to $18.9 \%$ at $t=5$ and to $18.8 \%$ at $t=10$. The former increase is associated with the demands from the scaling up, while the latter is related to the needs for concessional debt repayment. Although conditions improve slightly thereafter, by year 20, the VAT still remains above $18 \%$.

The government's protracted fiscal problems in the first years also stem from disappointing effects on private consumption and investment. Unfortunately, this disappointment is a robust feature of the transition path. Because savers cannot smooth consumption by borrowing from abroad (imperfect capital mobility) and non-savers live hand to mouth, the sharp increase in taxes translates into a reduction in consumption. The positive impact of increases in the stock of infrastructure on future productivity could spur, in theory, an immediate increase in private investment. But this is not

\footnotetext{
${ }^{41}$ The numerical simulations are free of approximation error. In all scenarios, the simulations track the global nonlinear saddle path. The solutions were generated by set of programs written in Matlab 7.7.0.471 (R2008b) and Dynare 4.1.1. See http://www.cepremap.cnrs.fr/dynare.
} 

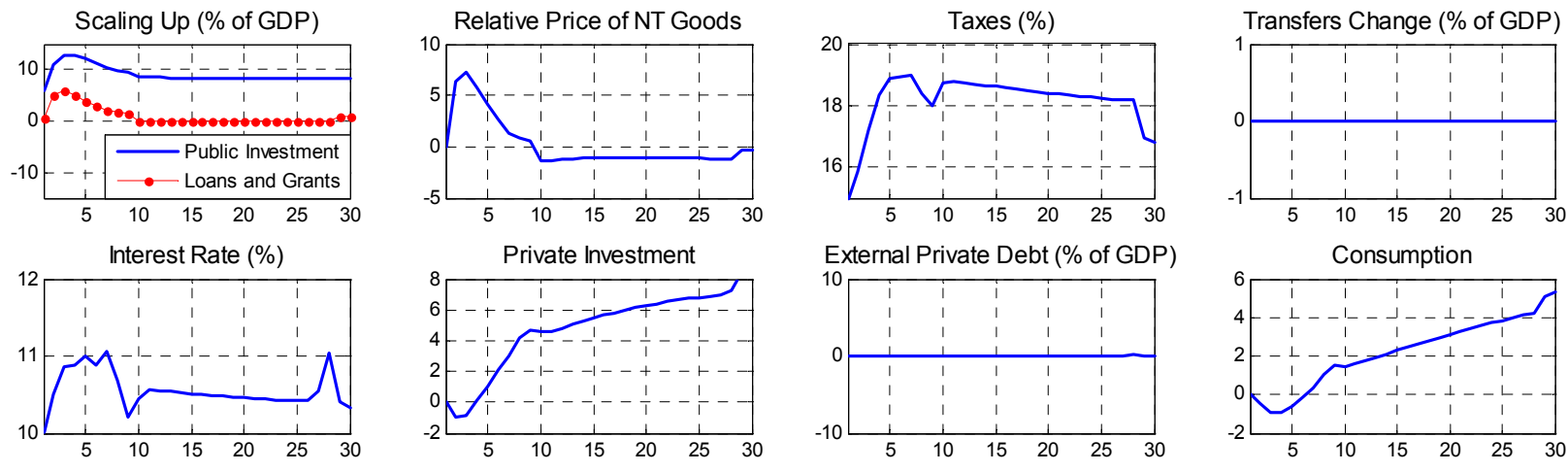

External Private Debt (\% of GDP)
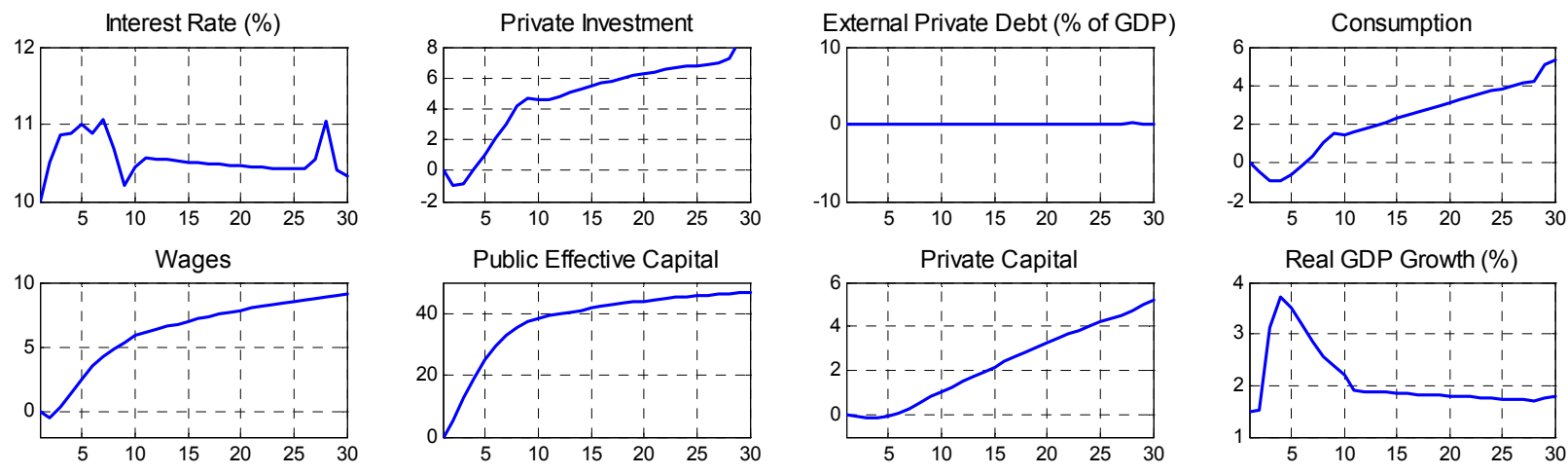

Public Effective Capital
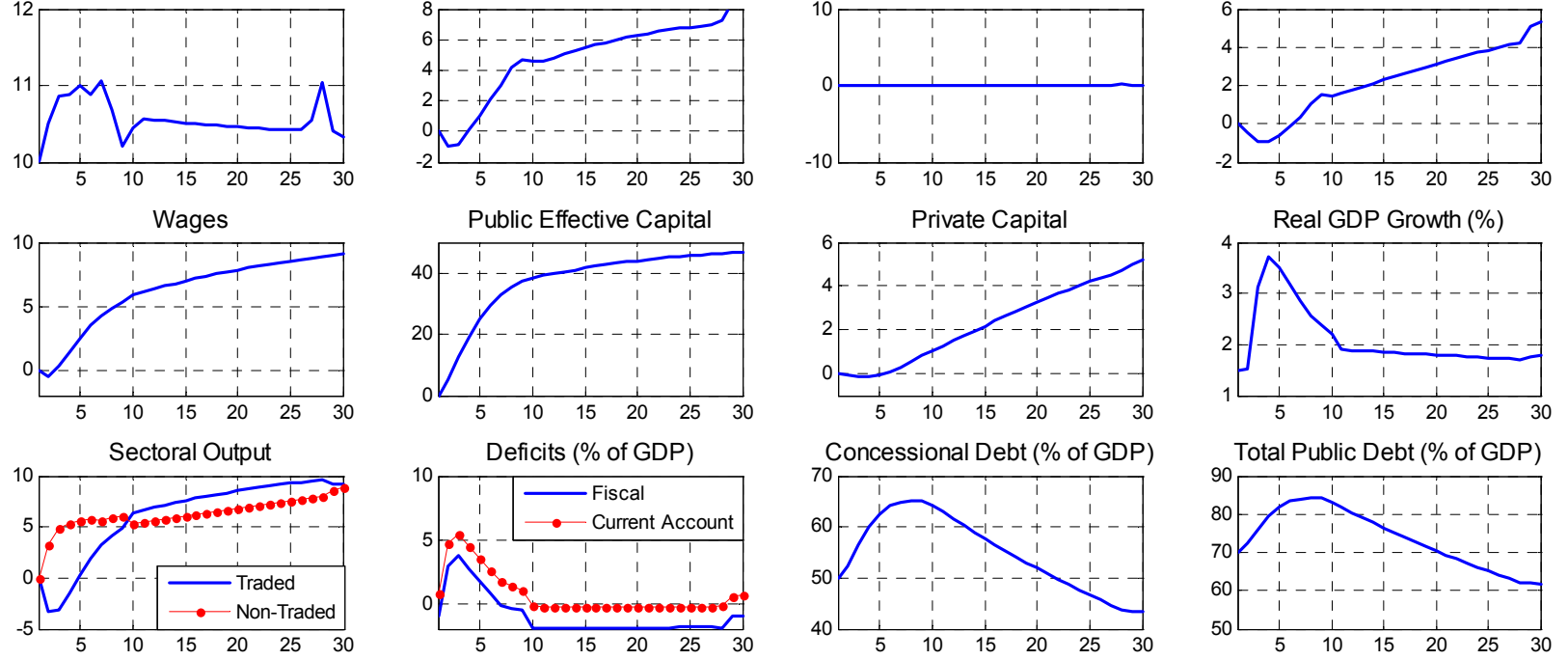

Figure 2: Base Case: Unconstrained Tax Adjustment. The transition path in the base case when the government takes out only concessional loans and the tax adjustment is unconstrained. Variables are expressed as percentage deviations from the initial steady state, unless otherwise noted. 
possible. In our base case, the increase in the real interest rate - a by-product of the significant VAT adjustment - is enough to force savers to cut investment in the short run. ${ }^{42}$ In summary, private consumption and investment contract relative to their initial steady state in the short run: by the year 2 consumption and investment decrease by about $1 \%$ and then stay depressed for another couple of years before they start rising slowly.

Due to the period of stagnant investment, growth of the private capital stock and real income lag far behind growth in the stock of infrastructure. At the typical 20-year horizon of the Excel-based DSAs and relative to the steady state, public capital has increased almost $45 \%$, which corresponds to the $90 \%$ of the $50 \%$ increase across steady states; but private capital is only about $3.3 \%$ higher (vs. almost $13 \%$ higher across steady states). ${ }^{43}$ Growth (in per capita terms) increases above $2 \%$ in the first decade, but by year 20 is close to $1.8 \%$, which is only 0.3 percentage points higher than the exogenously assumed long-run growth rate of $1.5 \%$. Because income and the tax base grow slowly during the borrowing phase, the government is ill-prepared for the subsequent repayment phase. The revenue demands of debt service keep the VAT above $18 \%$, which, in turn, slows the pace of capital accumulation and perpetuates the fiscal bind. Eventually policy makers are rewarded for their perseverance with a tiny revenue windfall and a moderate increase in the private capital stock, but this occurs in a distant future.

As expected, total public debt follows the sustainable path of concessional debt. Public debt peaks at year 8 reaching $84 \%$ of GDP and then declines as the country repays the concessional loans and GDP increases. Because, by construction, taxes always adjust to satisfy the government budget constraint, unstable dynamics for debt are ruled out from the analysis. Therefore the key question from the fiscal perspective is whether the tax adjustment is feasible in practice. For the base case, an increase from $15 \%$ to $18.9 \%$ of the VAT in four years seems implausible.

\section{A.2. More Optimistic and Troublesome Scenarios}

We study now the dynamic implications of changing some of the structural conditions of the economy. We consider conditions that represent optimistic and troublesome scenarios.

Panel A of Figure 3 shows the paths of the tax rate, consumption, and private investment of an optimistic scenario. The initial return on infrastructure is $35 \%$, user fees pay for all recurrent costs $f=1(\mu=0.1)$, and the public investment surge is fully efficient $s=1$. The paths of this scenario are notably better than those from the base case, especially in the medium term. The peak of the VAT, which occurs in the short run, is still high and close to $18 \%$. But the medium-term tax is much more

\footnotetext{
${ }^{42}$ To see why the interest rate rises when taxes go up significantly, recall the Euler equation for savers consumption, which can be written as:

$$
r_{t}=\frac{1+g}{\beta}\left(\frac{1+h_{t+1}}{1+h_{t}}\right)\left(\frac{c_{t+1}^{\mathfrak{s}}}{c_{t}^{\mathfrak{s}}}\right)^{1 / \tau}-1 .
$$

${ }^{43}$ It is common practice to discount econometric estimates of the q-elasticity of investment and assign $\Omega$ a value of 5-10 to speed up adjustment of the capital stock. That does not work in our case. When $\Omega=10$, the increases in private capital and real GDP are still small.
} 

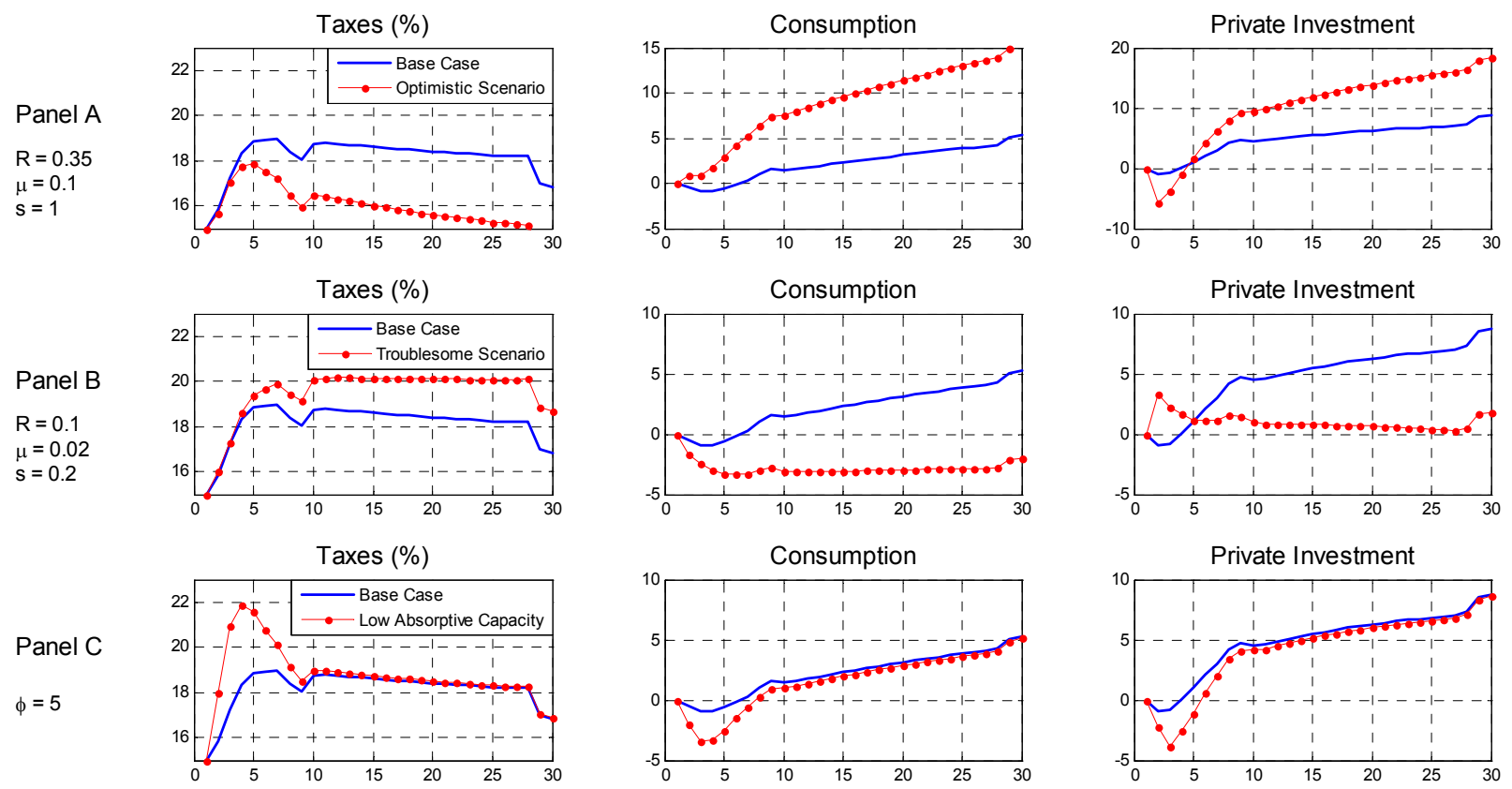

Figure 3: Unconstrained Tax Adjustment: Optimistic and Troublesome Scenarios. The transition paths for taxes, private consumption, and private investment in optimistic and troublesome scenarios, when the government takes out only concessional loans. Variables are expressed as percentage deviations from the initial steady state, unless otherwise noted. 
tolerable. By year 20, the tax is below 16\%. Moreover, consumption does not necessarily contract in the first years and by year 4, it is already on a fast growth trend. Interestingly, this optimistic scenario delivers a more pronounced short-term crowding out of private investment. The reason is simple. Since the capital account is closed, avoiding a consumption contraction in the short term is at the expense of reducing further private investment. Nevertheless, and relative to the base case, the robust medium term outlook of investment seems to compensate these initial negative effects.

It is also possible to simulate many troublesome scenarios. In the runs presented in panel B of Figure 3, the return on infrastructure is relatively low $R=0.1$, user fees finance only $20 \%$ of recurrent costs $f=0.2(\mu=0.02)$, and the public investment surge is very inefficient $s=0.2$. In this scenario, taxes climb to almost $20 \%$ in the year 7 and stay around this level during the debt repayment period. This depresses consumption by almost $4 \%$ in the short and medium term. Investment rises very timidly over time.

When, in addition, scaling up strains absorptive capacity, causing cost overruns of about $25 \%$ on new projects in the first year, the tax rate skyrockets to $22 \%$ by the fourth year (see Panel $\mathrm{C}$ of Figure 3). The consequences for consumption and private investment are dramatic. Relative to the initial steady state, consumption and investment fall by almost 4\%. As public investment reaches its new permanent level, the absorptive capacity costs diminish and consumption and private investment converge to similar paths to those of the base case.

Certainly, the size of the public investment surge determines the severity of the fiscal adjustment and the role that structural conditions of the economy play for this adjustment. Small public investment shocks lead to small and feasible tax adjustments. This is straightforward. As Figure 4 shows, when there is a small-scale expansion of public investment the tax adjustment of the economy even with bad structural conditions (e.g., very low return on public capital, user fees collection, efficiency, or absorptive capacity) is very similar to that of the base case. This, however, should not be taken as evidence to support the view that LICs should not improve their structural conditions. On the contrary, because of their dire infrastructure, for instance, LICs are in need of scaling up public investment; and, as Figures 3 and 4 reveal, it is precisely under a scaling up that bad structural conditions matter for the severity and the persistence of the tax adjustment.

\section{A.3. Gradually Increasing Transfers, Efficiency, and the Collection Rate of User Fees}

So far we have assumed that government transfers are constant in the analysis. Perhaps this is an extreme and, to some extent, shaky assumption of the base case. After all, even if public investment is not scaled up, LICs are expected to increase transfers associated with their anti-poverty programs in order to achieve the Millennium Development Goals (MDGs). Similarly, if public sector unions demand wage raises in line with those granted in the private sector, it will be difficult to prevent expenditure (transfers) from increasing. For these reasons, we examine a scenario where the government increases transfers over time. 


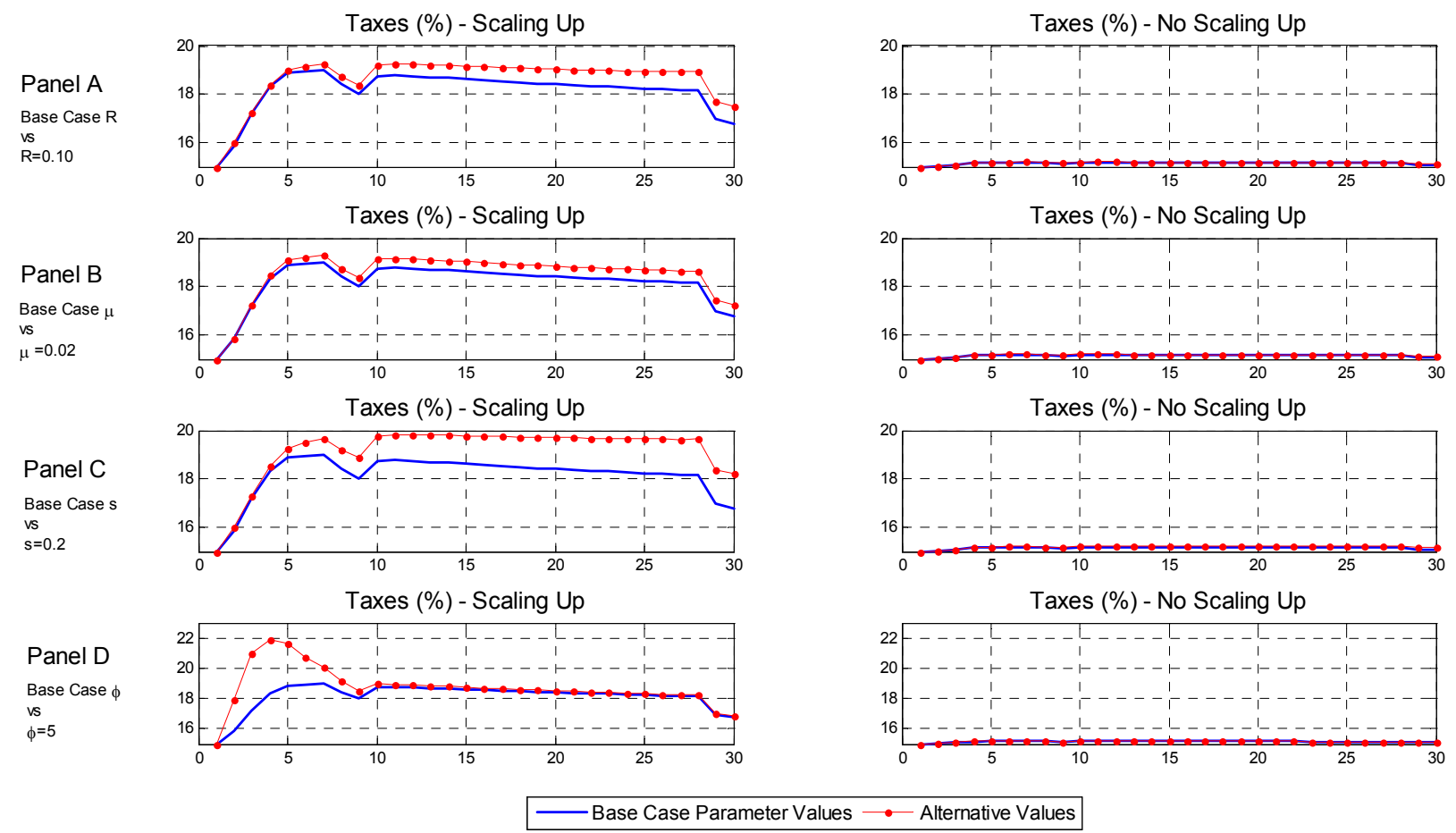

Figure 4: Unconstrained Tax Adjustment: The Size of the Scaling Up. Comparison of the tax adjustment with and without a scaling up of public investment, under different structural conditions. The increase of public investment in the no scaling up scenario corresponds to $5 \%$ of the increase in the scaling up scenario. 


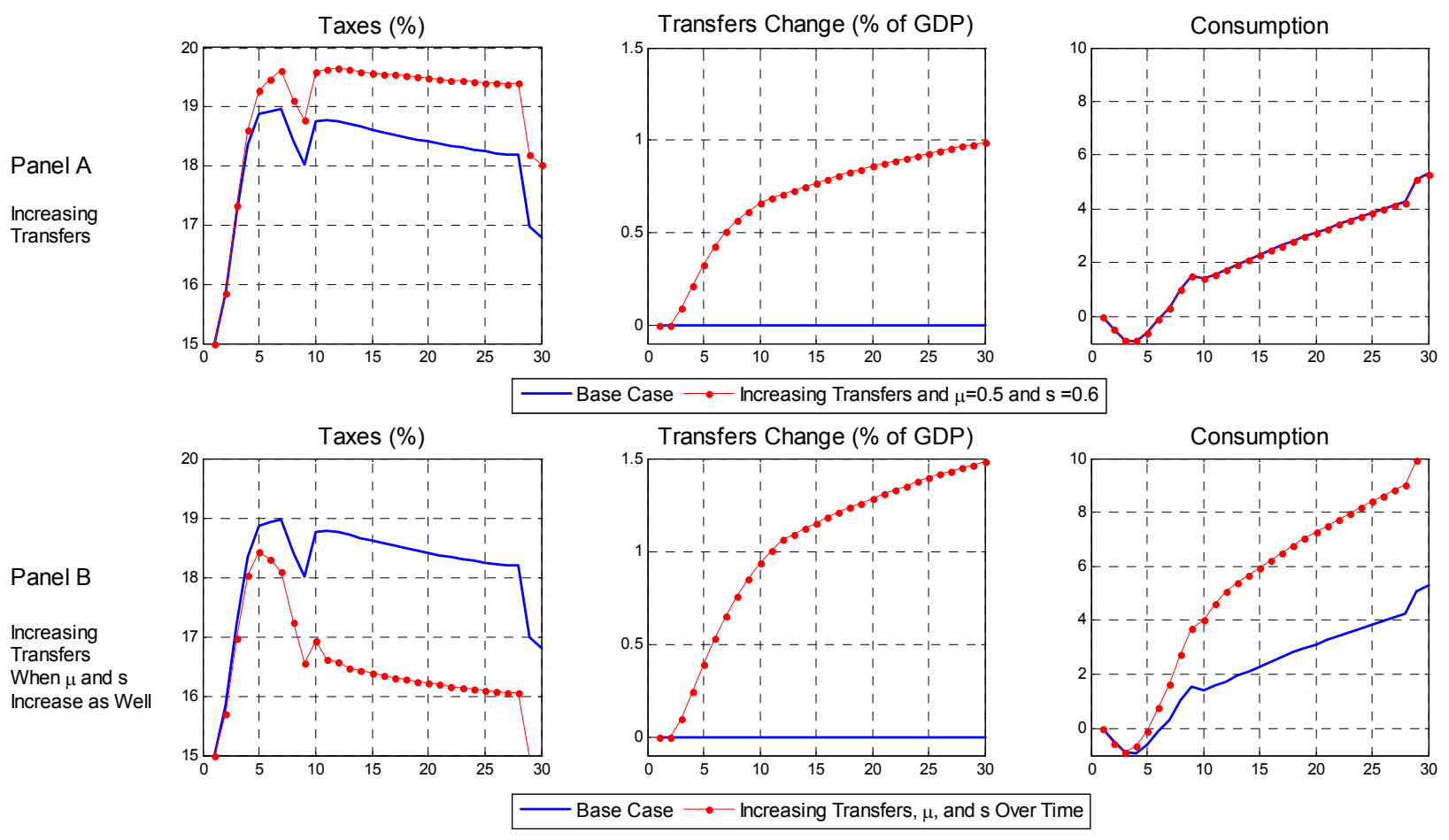

Figure 5: Unconstrained Tax Adjustment: Increasing Transfers. Comparison of the tax and private consumption adjustments in the base case and in the case when government transfers, the efficiency of public investment and user fees collection increase over time. Variables are expressed as percentage deviations from the initial steady state, unless otherwise noted.

Our framework is flexible enough to incorporate different rules for transfers. ${ }^{44}$ For expositional reasons, here we assume that transfers are raised as a fixed proportion $\mathfrak{m}$ of increases in real GDP as described by

$$
\mathcal{T}_{t}=\mathcal{T}_{o}+\mathfrak{m} \frac{\mathcal{T}_{o}}{y_{o}}\left(y_{t}-y_{o}\right)
$$

where $y_{t}^{r}=P_{x, o} q_{x, t}+P_{n, o} q_{n, t}$ is real GDP at period $t$. To fix ideas, assume $\mathfrak{m}=1$.

When transfers increase over time, the damage report for the fiscal adjustment is grim, while the consumption benefits are nil. As shown in panel A of Figure 5, taxes not only soar and reach a peak of $19.7 \%$ at $t=7$, but also stay above $19 \%$ over most of the debt repayment period. Of course transfers grow, and by year 20 their increase is above $0.6 \%$ of GDP. However, their effect on consumption is fully

\footnotetext{
${ }^{44}$ When $\lambda>0$, the fiscal adjustment falls on both taxes and transfers. In this case the model can still allow for scenarios with downwardly inflexible expenditure. For instance, transfers can be kept constant until growth generates a fiscal windfall according to $\mathcal{T}_{t}=\operatorname{Max}\left\{\mathcal{T}_{t}^{\text {target }}, \mathcal{T}_{o}\right\}$, where $\mathcal{T}_{t}^{\text {target }}$ is defined (26); or the government can be assumed to be unable to cut other expenditures to offset increases in public sector wages, implying that transfers evolve as$$
\mathcal{T}_{t}=\operatorname{Max}\left\{\mathcal{T}_{t}^{\text {target }}, \mathcal{T}_{o}+0.05 y_{o} \frac{\left(w_{t}-w_{o}\right)}{w_{o}}\right\}
$$

where the initial public wage bill is $5 \%$ of GDP and raises of this bill are as large as raises in private sector wages. 
offset by the more demanding tax adjustment. As a result, the path for consumption when transfers increase is practically the same as that when transfers are kept constant.

Does this mean that, in the context of public investment scaling ups, LICs cannot raise transfers without both suffering drastic tax adjustments and producing consumption benefits? The answer may lie, once more, on the key role that structural conditions, such as efficiency of public investment and the ability to collect user fees, play in the analysis. Unfortunately, there is evidence that these structural conditions are weak in LICs. The public investment management quality index of DablaNorris et al. (2011) suggests that there is a considerable variation across LICs. But their efficiency is in general lower than that of emerging and advanced economies. ${ }^{45}$ On the other hand, average user fees equal or slightly exceed average costs for operation and maintenances of physical infrastructure in SSA. But because of low collection rates, revenues cover only half of recurrent costs, as discussed by Briceño-Garmendia et al. (2008) and Eberhard et al. (2008).

Improving the efficiency of public investment and the collection rate of infrastructure user fees may allow LICs to increase transfers, while easing fiscal adjustment. Raising both structural conditions to $100 \%$ would capture more revenue not only from the expansion of infrastructure services, but also from services supplied by the existing network. Of course the prevalence of low efficiency and collection rates suggest that the problem is not easy to solve. But the transition from partial to full efficiency and collection does not have to occur overnight to greatly reduce the demands made on taxes. As shown in panel B of Figure 5, even when it takes a decade to complete the task, by year 20 the VAT is reduced to $16.2 \%$, whereas the increase in transfers is about $1.25 \%$ of GDP. As more infrastructure-related fiscal revenue is available, then the government can support a bigger increase in transfers than that of an economy where efficiency and the collection rate do not improve. More importantly with less tax adjustment and much higher transfers, consumption is boosted over the medium term.

Undoubtedly some governments will succeed in raising efficiency and the collection rate in upcoming decades, but this poses new questions.

First, even when efficiency improves, it is not clear whether the collection rate would be expected to rise or fall over time. The complicating factor is that scaling up public investment adds to the collection task by increasing the share of the population with access to infrastructure services. If collection capacity does not increase as fast as the supply of services, which is proportional to the stock of effective infrastructure, the collection rate might fall.

Second, if steady, systematic increases in efficiency and the collection rate are sure to happen in some country, then, given the magnitude of infrastructure deficits in LICs, policy makers should aim to scale up investment even more. A country that can achieve the paths shown in panel B of Figure 5 might choose not settle for an increase in public investment of $3 \%$ of initial GDP in the medium to long run; it could try to scale up much more. But this brings us back to the main scenario where the challenge is to ascertain how the scope for scaling up depends on feasible fiscal adjustments in the VAT.

\footnotetext{
${ }^{45}$ In fact, public management capacity constraints in themselves may call for further investments in capacity, i.e. "to invest in investing" in the words of Collier (2007).
} 


\section{B. Constrained Tax Adjustment Combined with External Commercial Borrowing}

The analysis of the previous section suggests that the transition can be challenging even when the investment is self-financing in the long run. The most obvious remedy, investigated next, is to borrow against future revenue gains in the external debt market with view to smoothing the path of fiscal adjustment.

Increasingly LICs have access to external debt markets. In recent years, Uganda, Tanzania, Senegal, Ghana, Angola, Congo DRC, Mali, Mauritania, and Rwanda have all entered into non-concessional loan agreements or issued sovereign bonds in international capital markets. Recognizing that the trend is likely to continue, the World Bank and the IMF have adopted a more flexible approach to non-concessional borrowing. The World Bank has introduced the IDA Non-concessional Borrowing Policy and the IMF has approved supplemental commercial loans for critical, large-scale infrastructure projects in countries with IMF-supported programs.

In this sub-section, we thus study the fiscal and macroeconomic implications of external commercial borrowing. In particular, the path of commercial debt is backed out from the government budget constraint

$$
d_{c, t}=P_{z, t} \mathbb{I}_{t}+\frac{1+r_{d}}{1+g} d_{t-1}-d_{t}+\frac{1+r_{d c, t-1}}{1+g} d_{c, t-1}+\frac{r_{t-1}-g}{1+g} P_{t} b_{o}+\mathcal{T}_{t}-h_{t} P_{t} c_{t}-\mathcal{G}_{t}-\mathcal{N}_{t}-\mu z_{t-1}^{e},
$$

while we assume the reactions functions described in (27)-(30) with $x=d_{c}$ determine the path for transfers and taxes. ${ }^{46}$ Concessional borrowing follows the same path as before and commercial loans are fully repaid $\left(d_{c}^{\text {target }}=0\right)$. These reaction functions subscribe to the view that the proposed borrowing and investment program is sustainable only if debt converges to a stationary level without violating sociopolitical constraints on how much and how fast fiscal policy can change. Inside the caps $h^{u}$ and $\mathcal{T}^{l}$, the parameters $\lambda_{1}-\lambda_{4}$ determine whether policy adjustment is slow or fast; setting these parameters requires a realistic assessment of the country's capacity for fiscal adjustment over different time horizons.

For expositional purposes, as in the case of concessional borrowing, in the experiments to follow we keep transfers constant. To do so we set the lower bound $\mathcal{T}^{l}$ equal to the initial value $\mathcal{T}_{o}$. By the reaction function (28), this ensures that $\mathcal{T}_{t}=\mathcal{T}_{o}$ at all times. Regarding the cap on taxes we set $h^{u}=0.17$ initially, but allow for a discrete jump at $t=8$ of 2 percentage points, so $h^{u}=0.19$.

\section{B.1. Tax Smoothing and Private Demand Crowding Out}

Access to the commercial debt market can make the dynamic transition associated with the scaling up smoother. Early on, non-concessional borrowing allows tax increases to be phased in more slowly.

\footnotetext{
${ }^{46}$ Note that this is equivalent to say that taxes and transfers are determined by the reactions functions (27)-(30), where $x=d_{c}$ and the gap $\mathfrak{G} \mathfrak{a p}_{t}$ is defined in (23); while the path of external commercial debt is determined by equation (24), which is a different way to express the government budget constraint.
} 

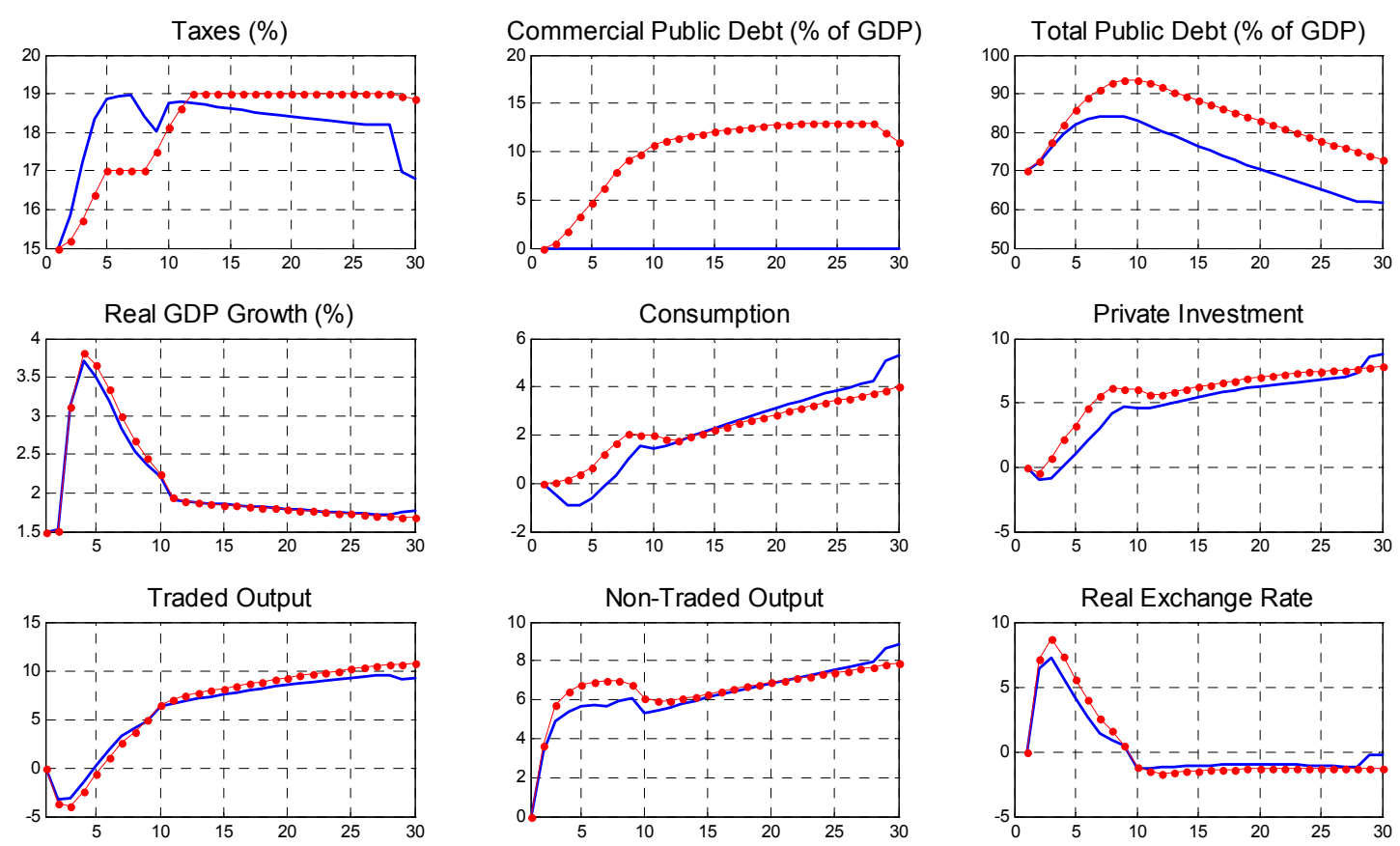

Unconstrained Tax Adjustment $\multimap-$ Constrained Tax Adjustment Combined with External Commercial Borrowing

Figure 6: Unconstrained Tax Adjustment versus Constrained Tax Adjustment with External Commercial Borrowing. Variables are expressed as percentage deviations from the initial steady state, unless otherwise noted.

Later, when the staggered limit of fiscal adjustment (upper bound on VAT) has been reached during the repayment phase for concessional debt, new borrowing can avert default or a collapse in public investment. And even if scaling up is feasible without recourse to non-concessional debt, smoothing the path of $h$ with non-concessional borrowing improves welfare by reducing intertemporal distortions in consumption.

Commercial borrowing can indeed help with adjustment, as shown by the simulations in Figure 6. In these runs, the initial return on infrastructure is $25 \%$, but, due to a staggered cap on taxesfirst at $17 \%$ and then at $19 \%$ - and an assumed pace at which taxes can rise, scaling up is feasible only when external commercial borrowing supplements concessional loans. The commercial loans also help smooth the initial tax adjustment: it takes 11 years, instead of the 6 years of the base case, to raise taxes from $15 \%$ to $19 \%$. The country rides these fiscal constraints until growth finally generates enough revenue to reconcile repayment of commercial debt with decreases in the VAT. Relative to the base case of concessional borrowing only, it is particularly impressive that private consumption and, to some extent, private investment do not decline in the first years. Thus the private demand crowding out problem seems to be practically gone. And although there is a more pronounced real appreciation, the short-term negative impact on traded output is not much worse than that of the base case. In the medium term, both the traded and non-traded sectors take off, generating more than sufficient economic growth to make public debt sustainable. 


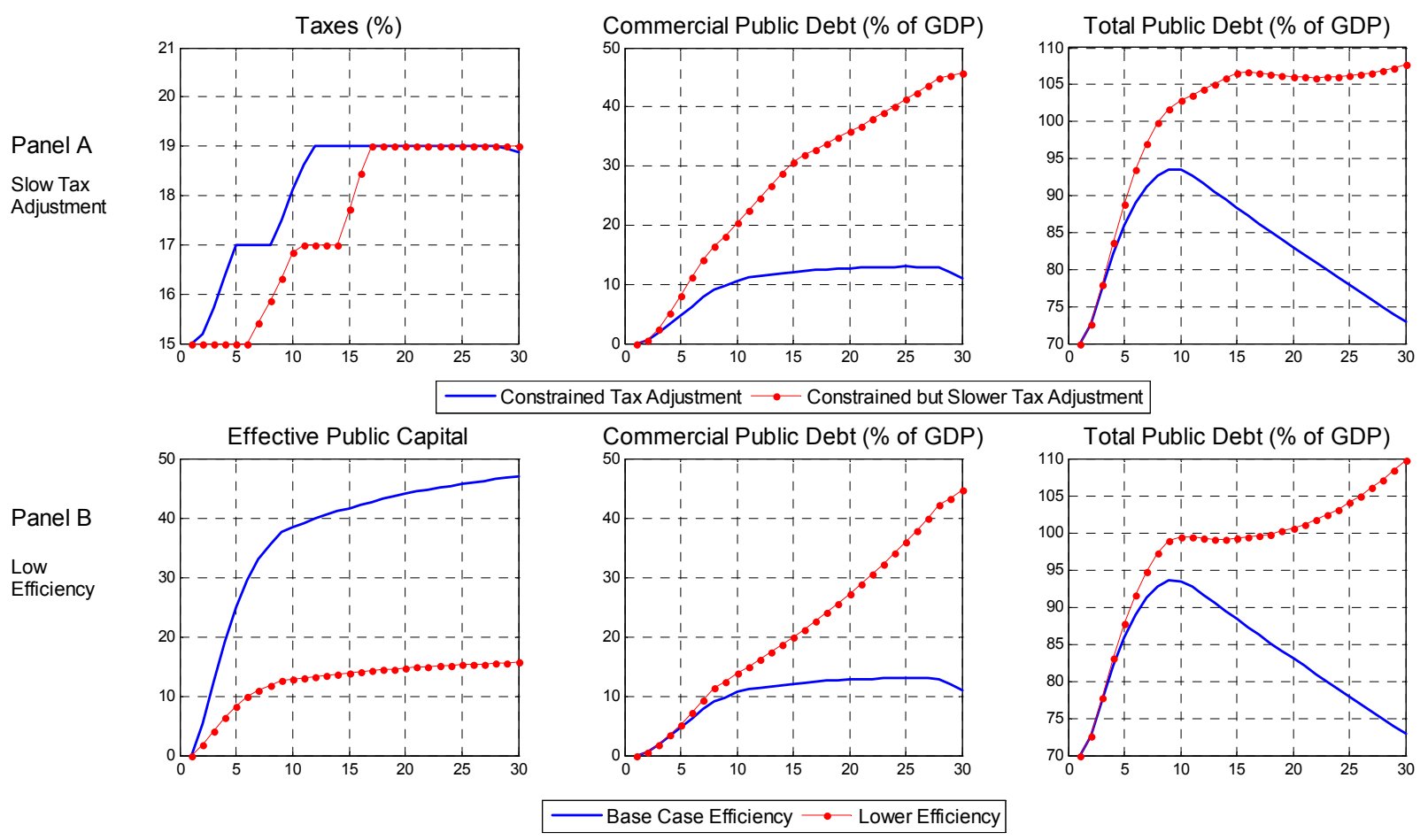

Figure 7: Constrained Tax Adjustment with External Commercial Borrowing: Varying the Structural and Policy Conditions.The transition paths for taxes and debt when the fiscal adjustment is slower or public investment is very inefficient.

\section{B.2. Debt Blowups: Structural and Policy Conditions}

There are also risks, of course, to taking out additional, more expensive debt. If non-concessional borrowing serves merely to delay the day of reckoning for an unsound investment program, then the ensuing debt crisis will be more costly and more traumatic than otherwise. If extra credit does more than facilitate fiscal adjustment, if instead it diminishes fiscal effort too much for too longone interpretation of delaying the initial tax adjustment and lowering the values for $\lambda_{1}$ and $\lambda_{2}$ in the reaction function (29) - the country may end up in a debt crisis. Borrowing-on-all-fronts is a high-risk, high-return strategy. It may greatly enhance the prospects for debt sustainability or lead to spectacular failure; much depends on the fine details governing debt contracts, the structural conditions of the economy, the dynamics of growth, and the speed of fiscal adjustment.

Policy makers might overestimate their capacity for fiscal adjustment, finance low-return projects, misplace the blueprints for reforms to improve governance and the efficiency of public investment, or repeatedly succumb to the temptation to put off necessary but unpopular tax increases and expenditure cuts. In this event we get some dreadful results, as exemplified in Figure 7. The run in Panel A simulates the case when the government delays raising the VAT. Because of this delay, the government loses the race against time and the debt blows up. In Panel B the government borrows heavily in 
the commercial market as it pays off its concessional debt, counting on growth in future tax revenues to ensure debt sustainability. But since public investment is very inefficient $(s=0.2)$ little effective public capital is accumulated, so future revenue gains are too small to stabilize the debt or even to prevent it from increasing at an accelerating rate. Similar results of explosive debt growth obtain if the return on public capital, the capacity to collect user fees or the absorptive capacity are low enough.

\section{Constrained Tax Adjustment Combined with Domestic Borrowing}

Although the DSAs have traditionally focused on the public external public debt, there is broad agreement that domestic debt plays an important role in overall debt sustainability. The IMF emphasizes that better integration of domestic debt into the DSF is critical to early detection of external debt vulnerability. In a similar vein, UNCTAD (2004) has warned that controlling growth of domestic debt may prove the main obstacle to debt sustainability in many LICs.

Accordingly, our last financing scenario involves a government that can sell debt in the domestic market but not in world capital markets. Domestic debt is then determined by the government budget constraint according to

$$
P_{t} b_{t}=P_{z, t} \mathbb{I}_{z, t}+\frac{1+r_{d}}{1+g} d_{t-1}-d_{t}+\frac{1+r_{t-1}}{1+g} P_{t} b_{t-1}+\mathcal{T}_{t}-h_{t} P_{t} c_{t}-\mathcal{G}_{t}-\mathcal{N}_{t}-\mu z_{t-1}^{e}
$$

whereas the reactions functions described in (27)-(30) with $x=b$ still determine the path for transfers and taxes. ${ }^{47}$ Concessional borrowing follows the same path described in the calibration section and new domestic loans are fully repaid $\left(b^{\text {target }}=0.2\right)$. As before, for expositional purposes, we assume that all the burden of the fiscal adjustment fall on taxes; so we set $\mathcal{T}^{l}=\mathcal{T}_{o}$ in (28), implying $\mathcal{T}_{t}=\mathcal{T}_{o}$ at all times. We also assume that there is a staggered structure for taxes: $h^{u}=0.17$ initially and then jumps to $h^{u}=0.19$.

Domestic borrowing is more prone to trigger unsustainable public debt dynamics than external commercial borrowing. This is for two reasons. Perhaps the most obvious is that domestic loans are more expensive than other sources of financing. In our calibration, the real interest rate on domestic loans at the initial steady-state equilibrium is 4 percentage points higher than the rate paid on external commercial debt. ${ }^{48}$ Moreover, it rises with more domestic borrowing. The second reason domestic borrowing is less effective is that it does not provide additional resources from abroad. Instead of taxing residents to extract the resources necessary to finance the higher public investment, the government borrows from them. But either way, the resources have to shift to the public sector, and the scaling up requires a crowding out of private consumption and investment. Thus if rates on domestic borrowing were the same as on foreign borrowing, the adjustment path would be much more

\footnotetext{
${ }^{47}$ Note that this is equivalent to say that taxes and transfers are determined by the reactions functions (27)-(30), where $x=b$ and the gap $\mathfrak{G} \mathfrak{a p}_{t}$ is defined in (23); while the path of domestic debt is determined by equation (24), which is a different way to express the government budget constraint.

${ }^{48}$ Interest payments on the internal debt are usually several times larger than interest payments on the external debt, exceeding $5 \%$ in some countries. Barkbu et al. (2008) also note that empirical studies find that rising domestic debt significantly increases the likelihood of external debt distress.
} 

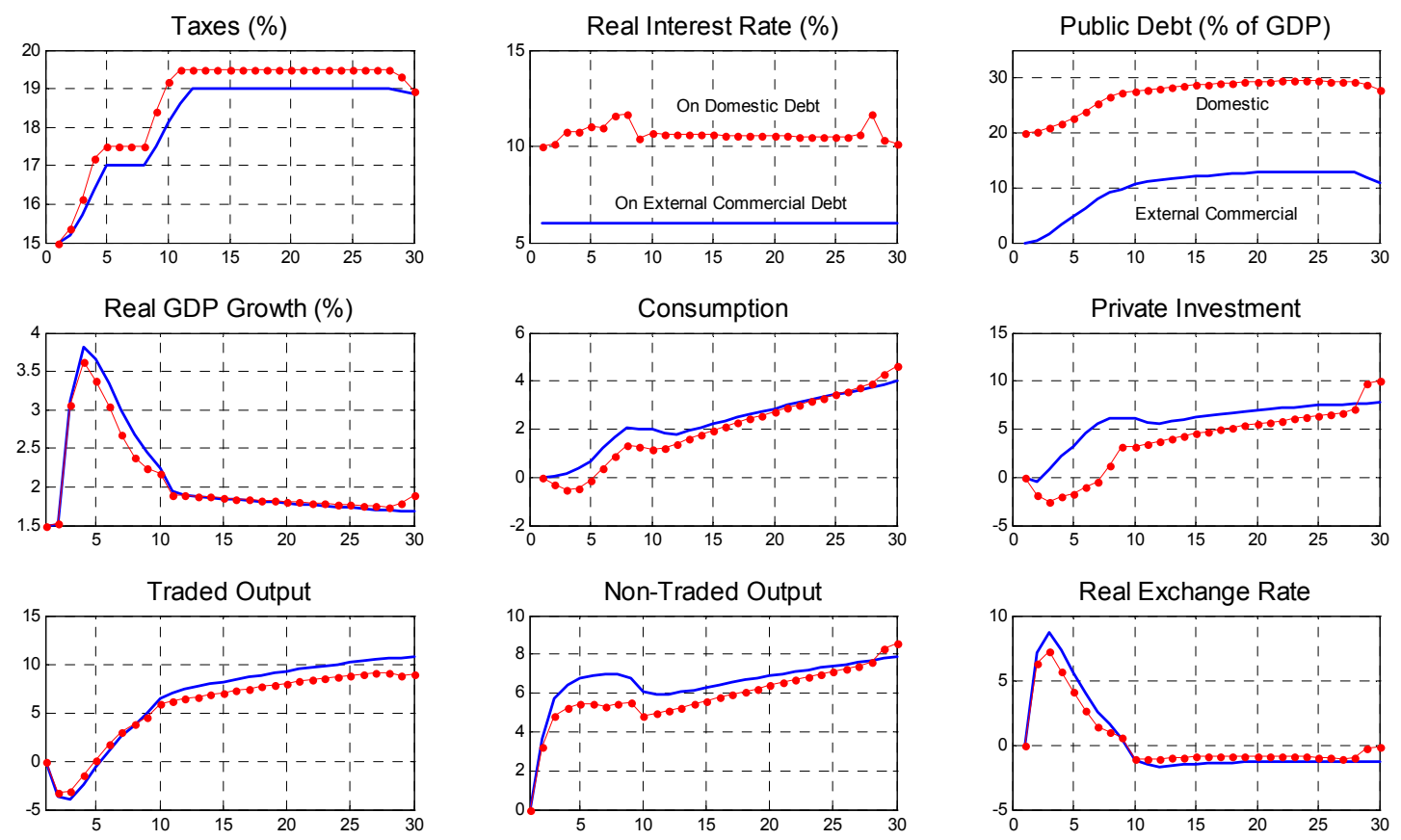

External Commercial Borrowing $\multimap$ Domestic Borrowing

Figure 8: Constrained Tax Adjustment: Domestic Borrowing versus External Commercial Borrowing. Variables are expressed as percentage deviations from the initial steady state, unless otherwise noted.

difficult with domestic borrowing. ${ }^{49}$

Given the calibration for domestic interest rates and other parameters, domestically-financed investment scenarios are thus more likely to be explosive. Recall that external commercial borrowing yields a sustainable trajectory with fiscal reaction functions implying that a $19 \%$ cap on the tax rate is delayed for more than 10 years. In the same scenario financed by domestic borrowing, public domestic debt explodes. To avoid this, the same changes to assumptions that eased adjustment with commercial borrowing would work here: a higher rate of return, higher efficiency, higher rate of user fee collection, a smaller investment scaling up, etc. To compare the macroeconomic dynamics associated with domestic borrowing to those with external commercial borrowing for nonexplosive scenarios, we now speed up fiscal adjustment in the domestic borrowing case to ensure debt sustainability. This can be achieved by raising the parameter $\lambda_{1}$ of the reaction function (29) from 0.25 to 0.45 and by increasing the original caps $h^{u}$ by 0.5 percentage points. As a result, in Figure 8 taxes go up to $17.5 \%$ by $t=5$ and to $19.5 \%$ by $t=11$. We can see the higher interest rates and much higher degree of crowding out of private consumption and investment. Both combine to increase fiscal pressure and require that taxes stay at $19.5 \%$ percent for almost two decades.

\footnotetext{
${ }^{49}$ This is analogus to a spend-and-don't-aborb response to aid surges and creates similar macroeconomic challenges, as analyzed in detail in Berg et al. (2010a)
} 

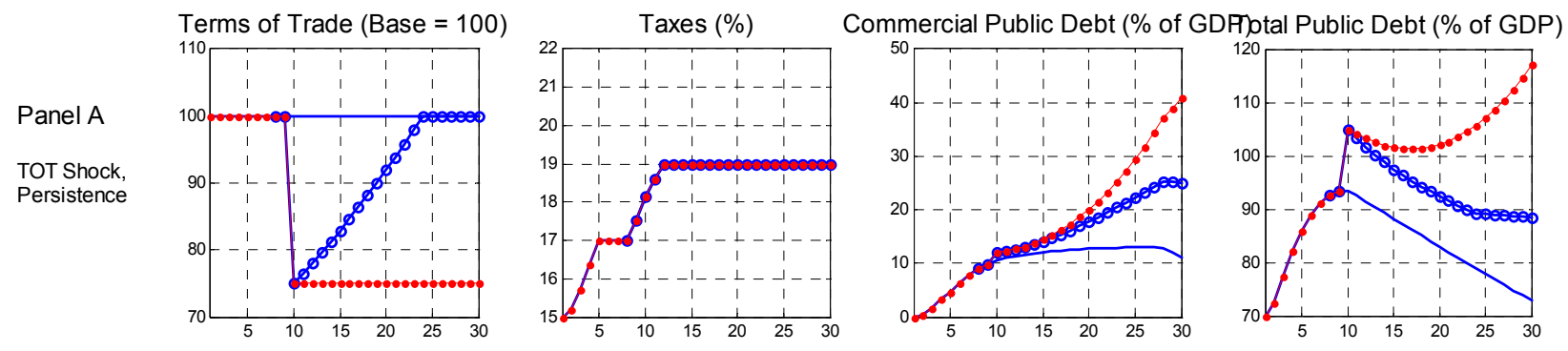

No Shock $\multimap$ Temporary TOT Shock $\longrightarrow$ Permanent TOT Shock
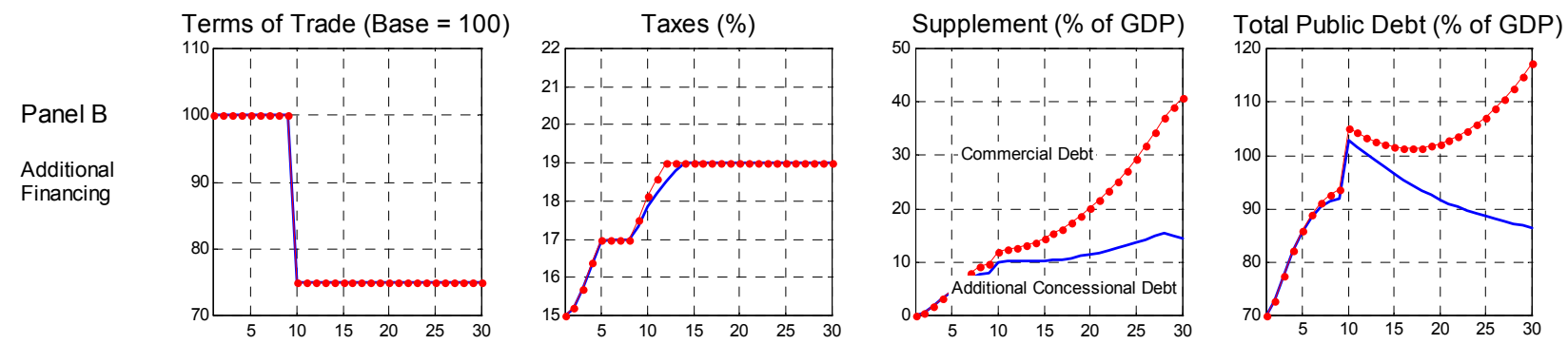

Figure 9: External TOT Shocks and Risks: Shocks Persistence and Financing Schemes. The paths of tax and public debt in the context of unexpected TOT shocks, with different degrees of persistence (temporary versus permanent) and financing sources to supplement concessional loans (external commercial borrowing versus more concessional borrowing), when tax adjustment is constrained

\section{External Shocks and Risks}

Our previous analyses have abstracted from the possibility of unexpected exogenous shocks. It is said, however, that LICs are particularly vulnerable to terms-of-trade shocks, natural disasters shocks, and other adverse exogenous shocks. ${ }^{50}$ This is to some extent due to the structural characteristics of these countries: LICs tend to be more dependent on primary commodities and have a higher exposure to natural disasters. Furthermore, as LICs become more financially integrated to the rest of the world by borrowing in capital markets, they will start resembling emerging economies. As such, they will be subject more frequently to risk premium shocks that affect the volatility of the real interest rate at which they can borrow. ${ }^{51}$

We proceed then to investigate the implications for debt sustainability of big unexpected negative

\footnotetext{
${ }^{50}$ For a discussion on importance of these external shocks in explaining the instability of output and the macroeconomic fluctuations in LICs, see Kose and Riezman (2001) and Raddatz (2007) and references therein.

${ }^{51}$ Neumeyer and Perri (2005), Uribe and Yue (2006) and Fernández-Villaverde et al. (2011) discuss how country risk premia, country spread and the volatility of the real exchange rate, respectively, affect business cycles in emerging economies.
} 
terms-of-trade (TOT) shocks, negative total-factor productivity (TFP) shocks ${ }^{52}$ — as a way to model natural disaster shocks - and shocks to the risk premium of public commercial debt. ${ }^{53}$ To model TOT shocks we assume a decline of $10 \%$ in the relative price of exports $P_{x, t}$ and an increase of $20 \%$ in the relative price of intermediate inputs $P_{m m, t}$, which together imply a negative shock of $25 \%$ to the TOT measured as $\frac{P_{x, t}}{P_{m m, t}}$. Negative TFP shocks are just introduced as a simultaneous and equal decrease of $5 \%$ in the productivity scale factors $a_{x}$ and $a_{n}$ in the technologies (1) and (2); while the risk premium shock is modelled as a jump in the premium $v_{g}$ that on impact raises the real interest rate on external commercial debt from $6 \%$ to almost $10 \%$. For this last shock we also turn on the mechanism in our model that allows for a variable government debt risk premium. This is achieved by setting $\eta_{g}$ at a positive value in our specification in equation (22). Following van der Ploeg and Venables (2011) we assume $\eta_{g}=1.89$.

In the analysis to follow we focus on the case where external commercial loans close the financing gap.

In addition, we concentrate on unexpected shocks that hit at the time when the economy is very vulnerable. We consider that this time is when the total public debt to GDP ratio would have reached a maximum, if shocks were absent. The relevance of this timing stems from the following reasons. It is precisely at this point in time when (i) public debt is more likely to breach one of the IMF-WB's DSF indicative thresholds or (ii) an unexpected adverse shock is most likely to place, in principle, public debt on an unsustainable path. ${ }^{54}$

Three results stand out from our analysis, summarized by the simulations presented in Figures 9 and 10 .

First, the persistence of the shock matters for debt sustainability. Panel A of Figure 9 shows the implications of varying the persistence of an unexpected TOT shock. It is clear that when the shock is temporary, the country manages a tax adjustment that is sufficient to avoid explosive dynamics for public commercial debt. Hence public debt is sustainable. But as the persistence of the shock increases, the debt outcome may become gloomy. If the shock were permanent, the adjustment would become insufficient, given the caps on taxes. Therefore, if shocks are persistent enough, debt sustainability

\footnotetext{
${ }^{52}$ Kraay and Nerhu (2006) find that shocks to real GDP growth are highly significant predictors of debt distress.

${ }^{53}$ Because in our analysis there is perfect foresight, to model unexpected shocks we have to paste two dynamic systems. Consider, for instance, how to model unexpected TOT shocks. In this case, the first system ignores TOT shocks and gives us the dynamic paths for all the endogenous variables under the public investment scaling up. This allows us to retrieve the values of these variables for any particular time when we want to hit the economy with the TOT shock. Assume that, without loss of generality, this time corresponds to $t=9$. Then we run a second system that (i) has as initial conditions for endogenous and exogenous variables the values retrieved from the first system at $t=9$, (ii) includes the TOT shocks and (iii) appropriately incorporates the continuation values for the rest of exogenous variables such as public investment, grants, and concessional borrowing. The final path for each variables is then constructed by pasting the series of the first system up to $t=9$ and the series of the second system beyond this point. Note that by our perfect foresight assumption, this methodology implies that the initial decrease in TOT shocks is the unexpected part. The rest of the shock, beyond $t=9$, is still expected. We leave for further work the generalization of this procedure to look at sequences of unexpected shocks, though because of the perfect foresight assumption, we cannot allow agents to react to uncertainty per se.

${ }^{54}$ There is nothing, however, that prevents the possibility of explosive debt dynamics if the unexpected shock hits the economy at any point in the rising path of debt.
} 

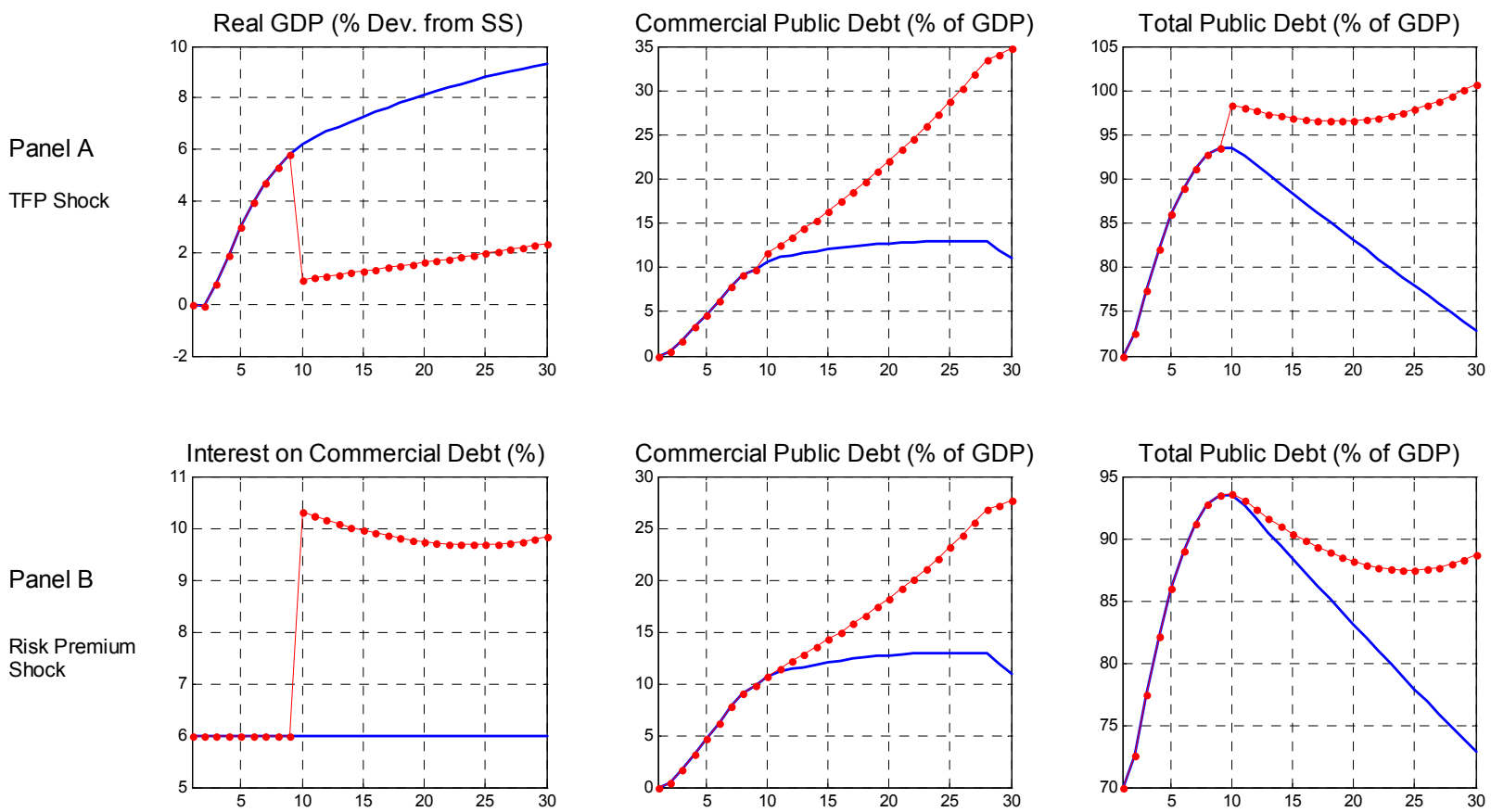

No Shock $\longrightarrow$ Permanent Shock

Figure 10: TFP and Risk Premium Shocks and Risks. The paths of tax and public debt in the context of unexpected TFP and risk premium shocks, under constrained tax adjustment combined with external commercial borrowing. 
problems may easily arise. Of course, this also depends on the magnitude of the shocks and the scale of additional public investment.

Second, in the context of unexpected shocks, additional concessional financing instead of external commercial loans could greatly reduce the risks of debt unsustainability. Panel B of Figure 9 shows that when an unexpected TOT shock hits the economy, additional concessional borrowing to finance the public investment surge, while setting caps in the tax adjustment, can ensure debt sustainability. In contrast, using commercial loans may be risky, as unsustainable debt paths become feasible. The crux of the matter is whether LICs can obtain additional aid in the event of adverse shocks.

Third, unexpected TFP shocks or government debt risk premium shocks can also induce explosive paths for public debt when the government contracts commercial loans. This is shown in Figure 10 that presents the effects on debt accumulation of permanent negative TFP shocks and government debt premium shocks. As the reader can easily infer from this figure, similar considerations to those we raised in the context of TOT shocks - shock persistence and type of additional financing - apply to these shocks. The risk premium shock case is interesting because it captures the idea that if market fears of debt repudiation rise and the risk premium rises with the stock of debt, borrowing and investment programs that were previously sustainable may become unsustainable. ${ }^{55}$

Summarizing, our analysis of unexpected shocks reveals that the strategy of external commercial borrowing, although a valuable resource for development, may be risky because it may give rise to public debt sustainability problems. Size matters here as well: the smaller the scaling up, the larger the unexpected shock required to cause explosive behavior.

\section{Concluding Remarks}

In this paper we have developed a fully-articulated, dynamic macroeconomic model to support debt sustainability analysis in low-income countries. Our model allows for financing schemes that mix concessional, external commercial, and domestic debt, while taking into account the impact of public investment on growth and constraints on the speed and magnitude of fiscal adjustment. In this regard, our model can help country authorities, IMF country teams, and others build a wide variety of logically consistent scenarios of public investment surges and other shocks, to inform and complement the currently used Excel-based DSA. Follow-on work will develop the apparatus to bring the model to data and conduct DSAs in a build-and -distribute approach.

We calibrate the model to the "average" LIC and provide simulations for a public investment surge, showing the macroeconomic consequences and potential risks associated with different financing schemes. We find that when the economy can only borrow concessionally to cover part of the surge, difficult fiscal and private sector adjustments seem unavoidable in the short to medium term, especially when the surge is front-loaded and the structural conditions of the economy are weak. The strategy

\footnotetext{
${ }^{55} \mathrm{~A}$ more interesting but much more challenging approach will be to endogenize default in the model and make the risk premium depend on the model-consistent risk of default.
} 
of allowing for external commercial borrowing in LICs may ease these adjustments; but the presence of weak structural and policy conditions and/or unexpected exogenous shocks calls for caution, as this strategy is also prone to induce unsustainable public debt dynamics. Domestic borrowing, on the other hand, is not as effective as external commercial borrowing, because it does not provide additional external resources, requires more drastic fiscal adjustments, and worsens the crowding out of the private sector.

The model is already being used to support debt sustainability analysis in country cases. ${ }^{56}$ These applications have motivated extensions of the model, including considering external commercial borrowing and domestic borrowing at the same time, modeling regional market borrowing, studying the implications of financing public investment with natural resource revenues, modeling investment in security, and financial repression issues, among others.

Still, a number of additional exercises and extensions would be useful. The prospects for debt sustainability would depend on the composition of public investment, including in human capital. Our model now assumes that all new public investment is allocated to physical infrastructure projects with a short gestation period. But even infrastructure can take many years to come on line. And from a debt sustainability perspective, the distinctive feature of human capital investments is their long gestation period. Also, user fees finance a much smaller fraction of recurrent costs for education and health than for power, roads, and water and sanitation. The time profiles for supporting fiscal adjustment and debt are certain therefore to look very different from the time profiles for investment in physical infrastructure.

Another important extension will be to more systematically incorporate uncertainty and shocks. It may be feasible to generalize the method used to analyze specific shocks in Section VI. Stochastic processes could be assumed for exogenous shocks, to the terms of trade and TFP, for example. Some elements of parameter uncertainty, e.g., about the rate of return to public investment, might be explicitly addressed. ${ }^{57}$

Finally, we have not investigated the trade off between costs and benefits of higher long-run debt levels. All the scenarios examined here assume debt/GDP returns to initial levels. It is plausible, however, that by raising the long-run level of debt, a country can forgo some of the long-run benefits of the investment surge in return for an easier transition. In considering such scenarios, it would be important to consider the risks associated with carrying a permanently higher debt level.

\footnotetext{
${ }^{56}$ The model was used to evaluate the authorities' public investment scaling-up strategies in Togo in the context of the debt sustainability analysis. Moreover it was used to carry out counterfactual simulations using the projections of the macroeconomic framework underlying the standard Excel-based DSA. These simulations provided a useful check on the plausibility and internal consistency of the projections made in the DSA. See Andrle et al. (2012). The model has been also applied to Burkina Faso and is being applied to Afghanistan, Cape Verde, Cote d'Ivoire, Ethiopia, Ghana, and Senegal.

${ }^{57}$ See Clinton et al. (2010) as an example, in a different context.
} 


\section{Appendix}

\section{A. On Public Investment Efficiency, Rates of Return, and Growth}

This Appendix elaborates on the concept of "efficiency" and the closely related concept of the rate of return to public capital. It serves as background information for the calibration of efficiency and the rate of return. The bottom line is that the operator needs to be thoughtful when calibrating efficiency, particularly in considering what it might imply for the marginal product of effective capital. A change in the calibration of efficiency has two different interpretations: as a level change that applies to the past and the future, as when comparing two countries at a point in time; or as a change that applies to future investment but not the past, as for example because of an improvement in public financial management. It is up to the operator to decide which applies and whether other adjustments to the calibration are necessary in light of that interpretation.

In the analysis to follow, for simplicity, we assume that there is only one productive sector in the economy and set the long-run growth rate equal to zero.

"Efficiency" refers to the rate at which spending on public investment translates into public capital. The model distinguishes between the efficiency of steady-state public investment $(\bar{s})$ and the efficiency of the additional public investment associated with the surge $(s)$. Thus, reproducing equation $(20)$ from the text with $g=0$ :

$$
z_{t}^{e}=(1-\delta) z_{t-1}^{e}+s\left(i_{z, t}-\bar{\imath}_{z}\right)+\overline{s i}_{z}
$$

where $i_{z, t}$ is public investment (measured in real dollars), $\delta$ is the rate of depreciation of public capital, $\bar{\imath}_{z}=(\delta+g) \bar{z}$ is the public investment at the (initial) steady state, and $z_{t}^{e}$ is the stock of "effective" public capital. It is "effective" because it is what appears in the economy's production function:

$$
q_{t}=A_{t}\left(z_{t-1}^{e}\right)^{\psi}\left(k_{t-1}\right)^{\alpha}\left(L_{t}\right)^{1-\alpha} .
$$

The only nonstandard feature here is that $s$ and $\bar{s}$ are not necessarily equal to 1 . If they were, then the usual capital accumulation equation $z_{t}^{e}=(1-\delta) z_{t-1}^{e}+i_{z, t}$ would obtain. When they are less than 1, a given rate of public investment results in a smaller accumulation of effective public capital. What is the effect of additional public investment on growth, and how does it depend on efficiency? The starting point is that the effect of additional public investment on output - the marginal product of investment $\left(\frac{\partial q_{t}}{\partial i_{z, t-1}}\right)$ or $M P_{i_{z}}$ - depends on both the marginal product of effective public capital$\left(\frac{\partial q_{t}}{\partial z_{t-1}^{e}}\right)$ or $M P_{z^{e}}$ - and on the efficiency with which public investment spending translates into effective public capital:

$$
M P_{i_{z}} \equiv \frac{\partial q_{t}}{\partial i_{z, t-1}}=\left(\frac{\partial q_{t}}{\partial z_{t-1}^{e}}\right)\left(\frac{\partial z_{t-1}^{e}}{\partial i_{z, t-1}}\right)
$$

Consider first the marginal product of effective public capital $\left(M P_{z^{e}}\right)$, which is equal to the rate of return on effective public capital $\left(R_{o}\right)$ plus the depreciation rate $\delta$. Taking derivatives of the production function and rearranging terms (and suppressing time subscripts):

$$
M P_{z^{e}} \equiv\left(\frac{\partial q}{\partial z^{e}}\right)=\psi A\left(z^{e}\right)^{\psi-1}(k)^{\alpha}(L)^{1-\alpha}=\psi \frac{q}{z^{e}},
$$


That is, the marginal product of effective public capital is proportional to the production function parameter $\psi$ and the output/public capital ratio. The production function embodies decreasing returns to public capital, holding other factors constant, and given the value of the parameter $\psi$.

Efficiency has a simple direct effect: $\frac{\partial z^{e}}{\partial i_{z}}=s$ from equation (44). To understand efficiency, it may be useful to imagine that all the available public investment projects at a given point in time are ranked from highest to lowest rate of return. This ranking reflects the decreasing marginal product of public capital shown in equation (47). The marginal product is thus the return of the best project available. In a fully efficient investment process, when an additional dollar is spent, this next best project is chosen. Suppose, though, because of incompetence, corruption, or just imperfect information, a government chooses worse projects. A lower efficiency - a lower $s$ - is a measure of the degree of deviation from the optimal process. Another - and complementary - way to think about a value of $s$ below 1 is simply that a fraction of spending is literally wasted, e.g. misclassified as investment when it in fact just covers transfers to civil servants.

It would seem straightforward to obtain the growth impact of public investment. In calibrating the model, the operator chooses directly a value for the rate of return to effective public capital $R_{o}$, and thus of the marginal product of public capital. The computer can solve for the implied value of $\psi$, given the other parameters of the model. Meanwhile, assumptions about the efficiency parameters $s$ and $\bar{s}$ determine the value of $\frac{\partial z^{e}}{\partial i_{z}}$. These together determine the output effect of additional public investment from equation (46), holding other factors constant. The other parameters and assumptions in the model about fiscal policy, private sector behavior, "Dutch disease", and so on yield the overall macroeconomic impact of the investment surge.

There is an important potential complication, however: efficiency and the marginal product of public capital may be related. Whenever - as with the Cobb-Douglas specification of equation (45) the marginal product of public capital is declining with larger stocks of public capital, this marginal product will tend to be higher when efficiency has been low in the past. A country with a low value of $\bar{s}$, for a given rate of historical or steady-state public investment, will have a low stock of effective public capital $z^{e} .^{58}$ Because the stock of public capital is scarcer, the marginal product of public capital will tend to be higher. This makes some sense: if a country has difficulty converting spending into public capital, it will tend to have very little capital, and even a small increment could be highly productive; think of the first road from the capital city to the port.

In the specific but widely-used case of the Cobb-Douglas production function, which is that used in the model in the text, the $M P_{z^{e}}$ will vary inversely with $z^{e}$, and thus with $\bar{s}$, for a given value of .the production function parameter $\psi$. In this case, countries with different levels of efficiency $\bar{s}$ will have the same $M P_{i_{z}}$, holding output, rates of public investment, and other model parameters constant. Thus, a given increase in public investment spending will have the same effect on output whatever the value of $\bar{s}$, again given output, rates of public investment, and other model parameters. ${ }^{59}$

\footnotetext{
${ }^{58}$ To see this, it may help to note that, for a case in which $s=\bar{s}$, equation (44) can be solved iteratively to obtain: $z_{t}^{e}=s \sum_{t=1}^{\infty}(1-\delta)^{k} i_{z, t-k}$, so that $z_{t}^{e}$ is proportional to $s$.

${ }^{59}$ There is empirical support for declining marginal product of public capital and for the specific Cobb-Douglas version. Isham and Kaufman (1999) show that the ex post rate of return on World Bank-financed projects (which may correspond more closely to $M P_{z^{e}}$ than $M P_{i_{z}}$ ) rises with "good policy" (measured very generally as low inflation, free trade, and
} 
This inverse relationship between $\bar{s}$ and $M P_{z^{e}}$ has been overridden for the user of the model because, as was described above, the operator chooses $M P_{z^{e}}$ directly. This means that when the calibration of $\bar{s}$ is changed, the computer finds a different value of $\psi$ as required to preserve the value of the $M P_{z^{e}}{ }^{60}$

The upshot is that the operator needs to be thoughtful when calibrating efficiency, particularly in considering what it might imply for the marginal product of effective capital. In particular, a different calibration of $s$ can be understood in two different ways. It is thus up to the operator to decide which interpretation applies and whether it calls for other recalibrations:

- According to one interpretation, different calibrations of the value of $s$ represent a time-invariant level difference in efficiency, e.g. between two countries. Higher steady-state efficiency will imply a higher marginal product of public investment in the model, because the marginal product of public capital is given by assumption. ${ }^{61}$ However, the operator should consider whether this makes sense in a particular case. How is it that the country wastes less public investment, and thus presumably has a higher public capital stock, and yet still has the same marginal product of public capital?

- The second interpretation is that this represents a change in efficiency relative to the past. Such a change in efficiency through time will have an unambiguous effect on the marginal product of public investment. This is because it raises the effect of investment spending on the growth rate of public capital, with no potentially offsetting effect on the size of the stock. Thus, if the idea is that the country is improving its efficiency relative to its own history, then there is no need to reflect on possible implications for the marginal product of public capital.

Similar thoughtfulness would seem to apply in the application of the Fund's policy on nonconcessional borrowing (IMF, 2009b). The policy emphasizes the role of efficiency framed as the capacity to manage public resources well-along with debt levels - in determining whether non-concessional borrowing for public investment is warranted. But from equation (46), the $M P_{z^{e}}$ also matters for the growth - and hence the debt sustainability - impact of public investment. This may depend on the broad policy environment and on the scarcity of public capital, and thus could be negatively correlated with steady-state efficiency. Presumably, these considerations need to be brought in through case-by-case analysis as discussed in the policy.

so on) and falls with the capital/labor ratio. This implies decreasing $M P_{z^{e}}$. Arslanalp et al. (2010) estimate a CobbDouglas production function. They include a further term related to the level of public capital and find a negative coefficient, consistent with a deviation from Cobb-Douglas in which the $M P_{z}$ falls even faster than implied by CobbDouglas. Servén (2010) provides a direct test in the context of estimated production functions. He finds that the output elasticity of infrastructure (the percent change in output associated with a given percent change in infrastructure) does not vary with the stock of infrastructure per worker, supporting a Cobb-Douglas specification.

${ }^{60}$ This approach to calibration can be rationalized with the observation that different measures of policy are positively correlated: a country that cannot efficiently build an electrical grid probably is not good at keeping it running well. Thus, countries with low investment efficiency likely also have low marginal product of installed capital, for a given capital stock (i.e., a relatively low value of $\psi$ ). This offsets the negative effect of higher efficiency on the $M P_{z}$ e that operates through the stock of public capital.

${ }^{61}$ Whether $\bar{s}$ is actually recalibrated does not matter, because the effect of any such change on the marginal product of investment spending is undone by changes in $\psi$. 


\section{References}

Adam, C. and D. Bevan, 2006, "Aid and the Supply Side: Public Investment, Export Performance, and Dutch Disease in Low-Income Countries," The World Bank Economic Review, Vol. 20(2), pp. 261-290.

Agenor, R. and P. Montiel, 1999, Development Macroeconomics, $2^{\text {nd }}$ edition (Princeton, N.J.; Princeton University Press).

Agenor, R., 2010, "A Thoery of Infrastructure-Led Development," Journal of Economics Dynamics and Control, Vol. 34(5), pp. 932-950.

Andrle, M., A. David, R. Espinoza, M. Mills, and L.F. Zanna, 2012, "As You Sow So Shall You Reap: Public Investment Surges, Growth, and Debt Sustainability in Togo," IMF Working Paper, forthcoming.

Arestoff, F. and C. Hurlin (2006), "Estimates of Government Net Capital Stocks for 26 Developing Countries, 1970-2002," World Bank Policy Research Working Paper 3858.

Arslanalp, Serkan Fabian Bornhorst, Sanjeev Gupta, and Elsa Sze, 2010, "Public Capital and Growth", IMF Working Paper 10/175 (Washington: International Monetary Fund).

Arnone, M. and A. Presbitero, 2010, Debt Relief Initiatives: Policy Design and Outcomes, forthcoming (Ashgate).

Arrow, K., 1962, "The Economic Implications of Learning by Doing." Review of Economic Studies 29, 153-173.

Asea, P. and C. Reinhart, 1996, "Le Prix de l'Argent: How (Not) to Deal with Capital Flows." Journal of African Economies 5 (AERC Supplement), 231-272.

Barkbu, B., C. Beddies, and M. Le Manchec, 2008, "The Debt Sustainability Framework for Low-Income Countries." IMF Occasional Paper, No. 266.

Barro, R., 1990, "Government Spending in a Simple Model of Endogenous Growth," Journal of Political Economy, Vol. 98(5), pp. S103-26.

Barro, R. and X. Sala-i-Martin, 1992, "Public Finance in Models of Economic Growth," Review of Economic Studies, Vol. 59(4), pp. 645-61.

Berg, A., T. Mirzoev, R. Portillo, and L.F. Zanna, 2010a, "The Short-Run Macroeconomics of Aid Inflows: Understanding the Interaction of Fiscal and Reserve Policy," IMF Working Paper 10/65.

Berg, A., J. Gottschalk, R. Portillo, and L.F. Zanna, 2010b, "The Macroeconomics of Medium-Term Aid Scaling-Up Scenarios." IMF Working Paper 10/160.

Berg, A., R. Portillo, S. Yang, and L.F. Zanna, 2012, "Public Investment in Resource Abundant Low-Income Countries," IMF Working Paper, forthcoming .

Blundell, R., 1988, "Consumer Behavior: Theory and Evidence - A Survey." Economic Journal 98, 16-65.

Blundell, R., P. Pashardes, and G. Weber, 1993, "What do we Learn about Consumer Demand Patterns from Micro Data?" American Economic Review 83, 570-597.

Briceño-Garmendia, C., K. Smits, and V. Foster, 2008, "Financing Public Infrastructure in Sub-Saharan Africa: Patterns and Emerging Issues." AICD Background Paper 15 (World Bank).

Bohn, H., 1998, "The Behavior of US Public Debt and Deficits," Quarterly Journal of Economics, Vol 113(3), pp. 949-963.

Calderón, C., E. Moral-Benito, and L. Servén, 2009, "Is Infrastructure Capital Productive? A Dynamic Heterogeneous Approach." Mimeo (World Bank). 
Calderón, C. and L. Servén, 2010, "Infrastructure in Latin America." Policy Research Working Paper, No. 5317 (World Bank).

Chatterjee, S. and S. Turnovsky, 2007, "Foreign Aid and Economic Growth: The Role of Flexible Labor Supply," Journal of Development Economics, Vol. 84(1), pp. 507-533.

Celasun, O., X. Debrun, and J. D. Ostry, 2007, "Primary Surplus Behavior and Risks to Fiscal Sustainability in Emerging Market Countries: A 'Fan-Chart' Approach," IMF Staff Papers, Vol. 53(3), pp. 401-425.

Cerra, V., S. Tekin, and S. Turnovsky, 2008, "Foreign Aid and Real Exchange Rate Adjustments in a Financially Constrained Dependent Economy," IMF Working Paper 08/204.

Clinton, K., R. Garcia-Saltos, M. Johnson, O. Kamenik, and D. Laxton, 2010, "International Deflation Risks under Alternative Macroeconomic Policies," Journal of the Japanese and International Economies, Vol. 24(2), pp. 140-177.

Collier, P., 2007, "The Bottom Billion: Why the Poorest Countries are Failing and What Can Be Done About It," Oxford University Press, New York.

Cowan, D., 2010, "Sub-Saharan Africa Macro View." Citigroup Global Markets.

Dabla-Norris, E., J. Brumby, C. Papageorgiou, A. Kyobe, and Z. Mills, 2011, "Investing in Public Investment: An Index of Public Investment Management Quality," IMF Working Paper, 11/37.

Dagher, J., J. Gottschalk, and R. Portillo, 2012, "The Short-run Impact of Oil Windfalls in Low-income Countries: A DSGE Approach." Journal of African Economies, forthcoming.

Dalgaard, C. and H. Hansen, 2005, "The Return to Foreign Aid." Discussion Paper No.05-04, Institute of Economics, University of Copenhagen.

Deaton, A., and D. Muellbauer, 1980, Economics and Consumer Behavior (New York, Cambridge University Press).

Eaton, J., 2002, "The HIPC Initiative: The Goals, Additionality, Eligibility, and Debt Sustainability." Mimeo (Operations Evaluation Department, World Bank).

Eberhard, A., V. Foster, C. Bricendo-Garmendia, F. Ouedraogo, D. Camos, and M. Shkaratan, 2008, "Underpowered: The State of the Power Sector in Sub-Saharan Africa." AICD Background Paper 6 (World Bank).

Escribano, A., J. Guasch, and J. Pena, 2008, "Impact of Infrastructure Constraints on Firm Productivity in Africa." AICD Working Paper No. 9 (World Bank).

EURODAD, 2001, "Putting Poverty Reduction First." (European Network on Debt and Development)

EURODAD, 2009, "Review of the DSF: Bank \& Fund Declare Countries Can Borrow More." (European Network on Debt and Development)

Fedelino, A. and A. Kudina, 2003, "Fiscal Sustainability in African HIPC Countries: A Policy Dilemma?" IMF Working Paper, No. 03/187.

Fernández-Villaverde, J., P. Guerrón-Quintana, J. Rubio-Ramírez, and M. Uribe, 2011. "Risk Matters: The Real Effects of Volatility Shocks," American Economic Review, Vol. 101(6), pp. 2530-2561.

Foster, V. and C. Briceño-Garmendia, 2010, Africa's Infrastructure: A Time for Transformation, forthcoming (Agence Francaise de Developpement and the World Bank).

Futagami, K., Y. Morita, and A. Shibata, 1993, "Dynamic Analysis of an Endogenous Growth Model with Public Capital," Scandinavian Journal of Economics, Vol. 95(4), pp. 607-25. 
Garcia, M. and R. Rigobon, 2005, "A Risk Management Approach to Emerging Market's Sovereign Debt Sustainability with an Application to Brazilian Data," in Inflation Targeting, Debt, and the Brazilian Experience: 1999 to 2003, editors, Francesco Giavazzi, Ilan Goldfajn, and Santiago Herrera, MIT Press.

Ghosh, A., J. Kim, E. Mendoza, J. D. Ostry, and M. Qureshi, 2011. "Fiscal Fatigue, Fiscal Space and Debt Sustainability in Advanced Economies," NBER Working Papers 16782, National Bureau of Economic Research.

Glomm, Gerhard and B. Ravikumar, 1994, "Public investment in infrastructure in a simple growth model," Journal of Economic Dynamics and Control, Vol. 18(6), pp. 1173-1187.

Greiner, A., 2007, "An Endogenous Growth Model with Public Capital and Sustainable Government Debt," The Japanese Economic Review, Vol. 58(3), pp. 345-361.

Greiner, A., W. Semmler, and G. Gong, 2005, The Forces of Economic Growth: A Time Series Perspective, $1^{\text {st }}$ edition (Princeton, N.J.; Princeton University Press).

Gueye, C. and A. Sy, 2010, "Beyond Aid: How Much Should African Countries Pay to Borrow?" IMF Working Paper, No. 10/140.

Gupta, S., R. Powell, and Y. Yang, 2006, Macroeconomic Challenges of Scaling Up Aid to Africa: A Checklist for Practitioners (International Monetary Fund).

Hjertholm, P., 2003, "Theoretical and Empirical Foundations of HIPC Debt Sustainability Targets." Journal of Development Studies 39, 67-100.

Hulten, C., 1996, "Infrastructure Capital and Economic Growth: How Well You Use It May Be More Important Than How Much You Have." NBER Working Paper, No. 5847.

Hulten, C., E. Bennathan, and S. Srinivasan, 2006, "Infrastructure, Externalities, and Economic Development: A Study of Indian Manufacturing." World Bank Economic Review 20, xx-xx.

International Monetary Fund, 2007a, "Regional Economic Outlook: Sub-Saharan Africa," SM/07/319, available at http://www.imf.org/external/pubs/ft/reo/2007/afr/eng/sreo1007.pdf

International Monetary Fund, 2007b, "Ghana: Staff Report for the 2007 Article IV Consultation," SM/07/156, available at http://www.imf.org/external/pubs/ft/scr/2007/cr07210.pdf

International Monetary Fund, 2009a, "Changing Patterns in Low-Income Country Financing and Implications for Fund Policies on External Financing and Debt," SM/09/56, available at http://www.imf.org/external/np/pp/eng/2009/022509a.pdf

International Monetary Fund, 2009b, "Debt Limits in Fund-Supported Programs: Proposed New Guidelines", SM/09/215, available at http://www.imf.org/external/np/pp/eng/2009/080509.pdf

International Monetary Fund, 2010, "Staff Guidance Note on the Application of the Joint FundBank Debt Sustainability Framework for Low-Income Countries," SM/10/16, available at http://www.imf.org/external/np/pp/eng/2010/012210.pdf

International Monetary Fund and World Bank, 2006, "Applying the Debt Sustainablity Framework for Low-Income Countries: Post-Debt Relief," SM/06/364, available at http://www.imf.org/external/np/pp/eng/2006/110606.pdf

International Monetary Fund and World Bank, 2009, "A Review of Some Aspects of the Low-Income Country Debt Sustainability Framework," SM/09/216, available at http://www.imf.org/external/np/pp/eng/2009/080509a.pdf 
International Monetary Fund and World Bank, 2010, "Preserving Debt Sustainability in Low-Income Countries in the Wake of the Global Crisis," SM/10/76 , available at http://www.imf.org/external/np/pp/eng/2009/080509a.pdf

Isham, Jonathan and Daniel Kaufmann, 1999, "The Forgotten Rationale For Policy Reform: The Productivity of Investment Projects" Quarterly Journal of Economics, February, Vol. 114, No. 1, pp. 149-184.

Kose, M. A., and R. Riezman, 2001, "Trade Shocks and Macroeconomic Fluctuations in Africa," Journal of Development Economics, Vol. 65(1), pp. 55-80.

Kraay, A. and V. Nehru, 2006, "When Is External Debt Sustainable?," World Bank Economic Review, Vol. 20(3), pp. 341-365.

Lluch, C., A. Powell, and R. Williams, 1977, Patterns in Household Demand and Saving (London, Oxford University Press).

Mendoza, E. and M. Oviedo, 2004, "Public Debt, Fiscal Solvency and Macroeconomic Uncertainty in Latin America: The Cases of Brazil, Colombia, Costa Rica, and Mexico," NBER Working Papers 10637, National Bureau of Economic Research.

Neumeyer, P., and F. Perri, 2005, "Business Cycles in Emerging Economies: the Role of Interest Rates," Journal of Monetary Economics, Vol. 52(2), pp. 345-380.

Ogaki, M., J. Ostry, and C. Reinhart, 1996, "Saving Behavior in Low- and Middle-Income Developing Countries." IMF Staff Papers 43, 38-71.

Panizza, U., 2008, "Domestic and External Public Debt in Developing Countries." UNCTAD Discussion Paper, No. 188.

Perrault, J., L. Savard, and A. Estache, 2010, "The Impact of Infrastructure Spending in Sub-Saharan Africa: A CGE Modeling Approach.” Policy Research Working Paper, No. 5386 (World Bank).

Pritchett, L., 2000, "The Tyranny of Concepts: CUDIE (Cumulated, Depreciated, Investment Effort) is Not Capital." Journal of Economic Growth 5, 361-384.

Raddatz, C., 2007, "Are External Shocks Responsible for the Instability of Output in Low-Income Countries?," Journal of Development Economics, Vol. 84(1), pp. 155-187.

Redifer, L., 2010, "New Financing Sources for Africa's Infrastructure Deficit.” IMF Survey Magazine: Countries and Regions.

Sachs, J., 2002, "Resolving the Debt Crisis of Low-Income Countries." Brookings Papers on Economic Activity $1,257-286$.

Schmitt-Grohé, S. and M. Uribe, 2003, "Closing Small Open Economy Models," Journal of International Economics, Vol. 61(1), pp. 163-185.

Servén, Luis, 2010, "Infrastructure investment and growth", World Bank, in progress; presentation available at http://www.imf.org/external/np/seminars/eng/2010/spr/lic/index.htm

Steadman Group (2009), "Financial Access Survey for Financial Sector Deepening," Presentation.

Straub, S., 2008, "Infrastructure and Growth in Developing Countries: Recent Advances and Research Challenges." Policy Research Working Paper, No. 4460 (World Bank).

Thurlow, J., D. Evans, and S. Robinson, 2004, "A 2001 Social Accounting Matrix for Zambia." International Food Policy Research Institute (Washington, D.C.)

Thurlow, J., X. Diao, and C. McCool, 2008, "2004 Social Accounting Matrix: Malawi." International Food Policy Research Institute. 
Turnovsky, S., 1999, Methods of Macroeconomic Dynamics, $2^{\text {nd }}$ edition (Cambridge, Mass.; MIT Press).

Uribe, M. and V. Yue, 2006, "Country Spreads and Emerging Countries: Who Drives Whom?," Journal of International Economics, Vol. 69(1), pp. 6-36.

UNCTAD, 2004, "Analysis of Eligibility and Debt Sustainability Criteria of the HIPC Initiative." Chapter 2 in Debt Sustainablility: Oasis or Mirage? (United Nations Conference on Trade and Development).

van der Ploeg, F. and A. Venables, 2011, "Harnessing Windfall Revenues: Optimal Policies for Resource-Rich Developing Economies," Economic Journal, Vol. 121(551), pp. 1-30.

Wyplosz, C., 2007, "Debt Sustainability Assessment: The IMF Approach and Alternatives." HEI Working Paper, No. 03/2007 (Graduate Institute of International Studies, Geneva). 